\title{
Review
}

\section{Structure of small G proteins and their regulators}

\author{
Marcin Paduch, Filip Jeleń and Jacek Otlewski \\ Institute of Biochemistry and Molecular Biology, University of Wroctaw, Wroctaw, Poland
}

Received: 6 November, 2001; accepted: 27 November, 2001

Key words: small G protein, GTPase, Ras, Rho, GAP, GEF, GDI, protein tertiary structure, protein-protein interaction

\begin{abstract}
In recent years small $G$ proteins have become an intensively studied group of regulatory GTP hydrolases involved in cell signaling. More than 100 small G proteins have been identified in eucaryotes from protozoan to human. The small G protein superfamily includes Ras, Rho Rab, Rac, Sar1/Arf and Ran homologs, which take part in numerous and diverse cellular processes, such as gene expression, cytoskeleton reorganization, microtubule organization, and vesicular and nuclear transport. These proteins share a common structural core, described as the G domain, and significant sequence similarity. In this paper we review the available data on $\mathrm{G}$ domain structure, together with a detailed analysis of the mechanism of action. We also present small $G$ protein regulators: GTPase activating proteins that bind to a catalytic G domain and increase its low intrinsic hydrolase activity, GTPase dissociation inhibitors that stabilize the GDP-bound, inactive state of G proteins, and guanine nucleotide exchange factors that accelerate nucleotide exchange in response to cellular signals. Additionally, in this paper we describe some aspects of small G protein interactions with downstream effectors.
\end{abstract}

\footnotetext{
J.O. was supported by an International Scholar's award from the Howard Hughes Medical Institute.

${ }^{\circledR}$ Corresponding author: Jacek Otlewski, Institute of Biochemistry and Molecular Biology, University of Wrocław, Tamka 2, 50-137 Wrocław, Poland; tel. (48 71) 375 2824; fax. (48 71) 375 2608; e-mail: otlewski@bf.uni.wroc.pl

Abbreviations: Arf, ADP ribosylation factor; BH, breakpoint-cluster-region homology domain; CRD, cystein rich domain; DH, Dbl homology domain; FTIR, Fourier-transform infrared spectroscopy; GAP, GTPase-activating protein; GDI, guanine nucleotide dissociation inhibitor; GEF, guanine nucleotide exchange factor; GppCp, guanosine-5'-( $\beta, \gamma$-methylene)-triphosphate; GppNp, guanosine-5'-( $\beta, \gamma$-imido)triphosphate; GTP $\gamma \mathrm{S}$, guanosine- 5 '-( $\gamma$-thio)-triphosphate; ICE, interleukin $1 \beta$-convertase; $K_{\mathrm{d}}$, dissociation constant; $k_{\text {off }}$, dissociation rate constant; $k_{\text {on }}$, association rate constant; $\mathrm{PH}$, pleckstrin homology domain; LFER, linear free energy relationships; Pi, inorganic phosphate; PI3-kinase, phosphatidyl inositol 3-kinase; PtdIns(3,4) $\mathrm{P}_{2}$, phosphatidylinositol-3,4-bisphosphate; RBD, Ras binding domain; RGS, regulator of $\mathrm{G}$ protein signaling;
} 
Small G proteins (also known as small GTPases, small GTP binding proteins and Ras protein superfamily) form an independent superfamily within the larger class of regulatory GTP hydrolases. This superfamily is made up of a diverse range of molecules that control a vast number of important processes and possess a common, structurally preserved GTP-binding domain [1]. Small G proteins are monomeric molecules with masses in the range from 20 to $40 \mathrm{kDa}$, that bind and hydrolyze guanine nucleotides [2]. Although G proteins are poor catalysts, they can form stable complexes both with the substrate (GTP) and the product (GDP). The GTP and GDP-bound forms define the active and inactive state of the molecule, respectively. The binding and hydrolysis of guanine nucleotides cause significant conformational changes within so called the switch regions I and II of the protein $\mathrm{G}$ catalytic domain.

A wide range of available three-dimensional structures reveals the basis of protein $\mathrm{G}$ regulation and activity. The transition between the active and inactive states is aided by regulatory proteins of at least three distinct families. The low intrinsic GTPase activity is accelerated by the binding of the GTPase activating protein (GAP) which influences the duration of the GTP-bound form. The release and subsequent rebinding of guanine nucleotide is promoted by guanine nucleotide exchange factor (GEF). Finally, the ability to bind the effector is abolished in the presence of guanine dissociation inhibitor (GDI).

There are about 150 known eukaryotic small G proteins which have been characterized and divided into five families: Ras, Rho, Rab, Sar1/Arf and Ran [3]. Members of these families perform numerous cellular functions: Ras and Rho families are involved in gene expression, Rho proteins control cytoskeleton reorganization, Rab and Sar1/Arf families influence vesicular transport, and Ran $G$ proteins regulate nuclear transport and the cell cycle.

\section{GENERAL PROPERTIES OF SMALL G PROTEINS}

Numerous comparisons of amino-acid sequences of small $\mathrm{G}$ proteins from various species have revealed that they are conserved in primary structures at the level of $30-55 \%$ homology. Individual members of the Ras family share relatively high, about $50 \%$, amino-acid sequence identity, whereas Rab and Rho families show about 30\% sequence identity with Ras family members. All G proteins possess a consensus sequence responsible for GTP/GDP binding and GTPase hydrolytic activity [4].

The biological function of small $\mathrm{G}$ proteins strongly depends on postranslational modifications. For example, Ras, Rho and Rab families contain a C-terminal sequence which undergoes posttranslational modifications which are essential for the cellular localization of the proteins and their interaction with effectors. There are several possibilities of C-terminal region modifications, as described in Fig. 1. Probably the most important covalent modification is the attachment of isoprene moieties and lipids, together with methylation and proteolytic cleavage [5-7]. Posttranslational modifications have not yet been well characterized, and it is of high interest to study possible farnesyltransferase inhibitors that could be used as drugs in G protein-associated disease treatment [5, 8-10].

\section{G DOMAIN}

Crystallographic and NMR analysis of small G proteins, including Ha-Ras, Rho, Rac1, Rap2A, Rab3A, Rab7, Arf, Ran, Cdc42 revealed the presence of a $20 \mathrm{kDa}$ catalytic domain that is unique for the whole superfamily. The domain is built of five $\alpha$ helices (marked $\mathrm{A} 1-\mathrm{A} 5)$, six $\beta$-strands (B1-B6) and five polypeptide loops (G1-G5) (Fig. 2A). Contrary to a general rule that within different 

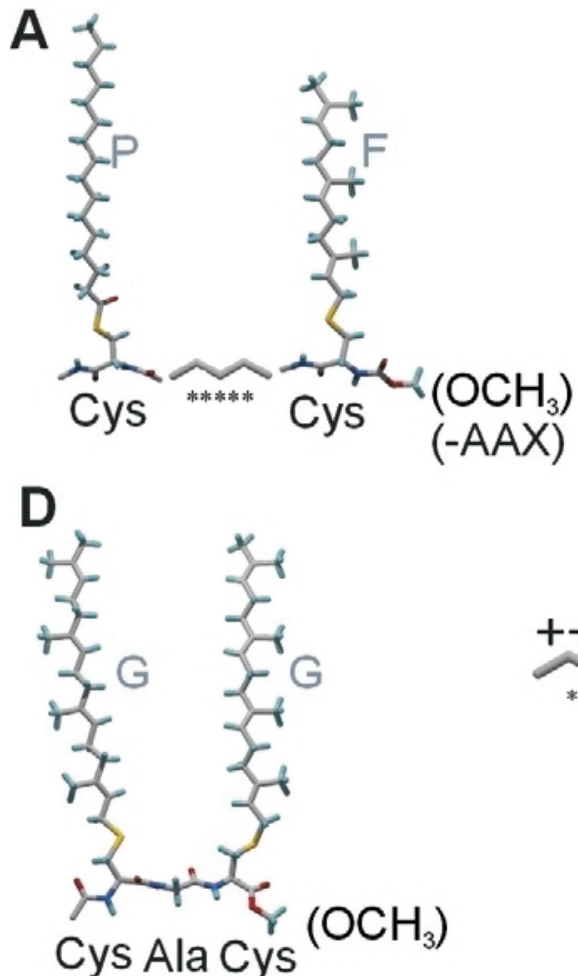
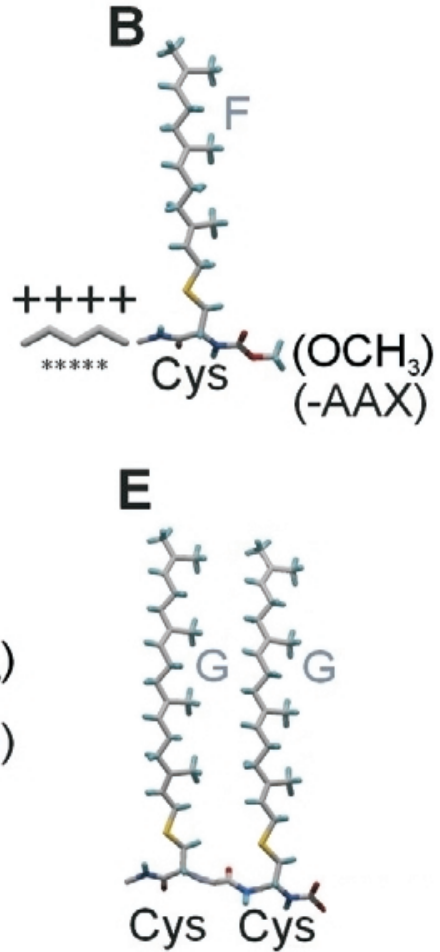

Figure 1. Posttranslational modifications of small G proteins.

C-terminal regions can be divided into five groups: A. H-Ras and N-Ras are palmitoylated and farnesylated, a short C-terminal peptide is proteolytically removed (-AAX) and the C-terminal Cys residue is carboxymethylated. B. K-Ras is modified in the same manner as H-Ras and N-Ras but does not possess the additional palmitoylated Cys residue, a polybasic region preceding the C-terminal Cys is present. C. Rap1 is geranylgeranylated, a short peptide (-AALeu/Phe) is removed, the polybasic region and carboxymethylation are also present. D. In Rab3a both Cys residues are geranylgeranylated and the C-terminal Cys is carboxymethylated. E. Cys-Cys seqence of Rab1 is geranylgeranylated and the C-terminal Cys is carboxymethylated. $\left(\mathrm{OCH}_{3}\right)$, indicates methylation; +, polybasic region; *, linker; A, aliphatic amino acid; X, any amino acid; P, palmitoyl; F, farnesyl; G, geranylgeranyl.

protein folds secondary structure elements are more conserved than loop regions, the most conserved structural elements of the $G$ domain are the loops (Table 1) [2, 11]. A structural comparison of the GTP- and GDP-bound form, allows one to distinguish two functional loop regions: switch I and switch II that surround the $\gamma$-phosphate group of the nucleotide (Fig. 2) [12, 13]. Switch III region, which is present in the $\alpha$ subunits of heterotrimeric G proteins, is absent in small $G$ proteins [14].

The G1 loop (also called the P-loop) that connects the $\mathrm{B} 1$ strand and the $\mathrm{A} 1$ helix is responsible for the binding of $\alpha$ - and $\beta$-phosphate groups. The G3 loop provides residues for $\mathrm{Mg}^{2+}$ and $\gamma$-phosphate binding and is located at the N-terminus of the A2 helix. The G1 and G3 loops are sequentially similar to Walker A and Walker B boxes that are found in other nucleotide binding motifs, not homologous to small $G$ proteins, present in sugar kinases, ABC transporters and ATP synthases [15]. The G2 loop connects the A1 helix and the B2 strand and contains a conserved Thr residue responsible for $\mathrm{Mg}^{2+}$ binding. The guanine base is recognized by the G4 and G5 loops. The consensus sequence NKXD of G4 loop contains Lys and Asp residues directly interacting with the nucleotide. Part of the G5 loop located between $\mathrm{B} 6$ and $\mathrm{A} 5$ acts as a recognition site for the guanine base (Fig. 3) [16]. A comparison of two complexes, Ras.GDP. $\mathrm{Mg}^{2+}$ and $\mathrm{Ras} \cdot \mathrm{Mg}^{2+}$, containing a nonhydrolyzable GTP analogue, GppNp or GppCp, reveals the presence of two regions that undergo structural changes upon GTP 
Table 1. Sequence alignment of conserved loops.

The most conservative amino-acid residues within the G1-G5 loops are indicated in colour, also consensus sequences are given. (SWISSPROT accession codes for all sequences are listed in the second column.).

\begin{tabular}{lllllll}
\hline Protein & Seqence & $\begin{array}{l}\text { G1 (P-loop) } \\
\text { GXxxxGK(S/T) }\end{array}$ & $\begin{array}{l}\text { G2 (switch I) } \\
\text { XTX }\end{array}$ & $\begin{array}{l}\text { G3 (switch II) } \\
\text { DXXG }\end{array}$ & $\begin{array}{l}\text { G4 } \\
\text { (N/T)(K/Q)D }\end{array}$ & $\begin{array}{l}\text { G5 } \\
\text { (T/G/C)(C/S)A }\end{array}$ \\
\hline H-Ras & P01112 & GAGGVGKS & YDPT I ED & I L DTAGQE & VGNKCD & Y I ETSAK \\
\hline RhoA & P06749 & GDGACGKT & YVPTVFE & L WDTAGQE & VGNKKD & YMECS AK \\
\hline Cdc42 & P25763 & GDGAVGKT & YVPTVFD & L F DTAGQE & VGTQ I D & Y VECSAL \\
\hline Rac1 & P15154 & GDGAVGKS & Y I P TVFD & L WDTAGQE & VGTKLD & Y L ECSAL \\
\hline Gi & P04898 & GAGE SGKS & RVKTTGI & L F DVGGQR & FL NKKD & T HF TCAT \\
\hline Arf-Tu & P20001 & GHVDHGKT & R GI TINT & HV DGPGHA & FL NKCD & I V RGSAL \\
\hline
\end{tabular}

binding and hydrolysis (Fig. 2). One of them is switch I, which corresponds to the G2 loop and is called the effector loop because it is a site for effector and GAP binding [17]. Switch II is formed by the G3 loop and part of the A2 helix and structurally is the most flexible element of the catalytic domain.

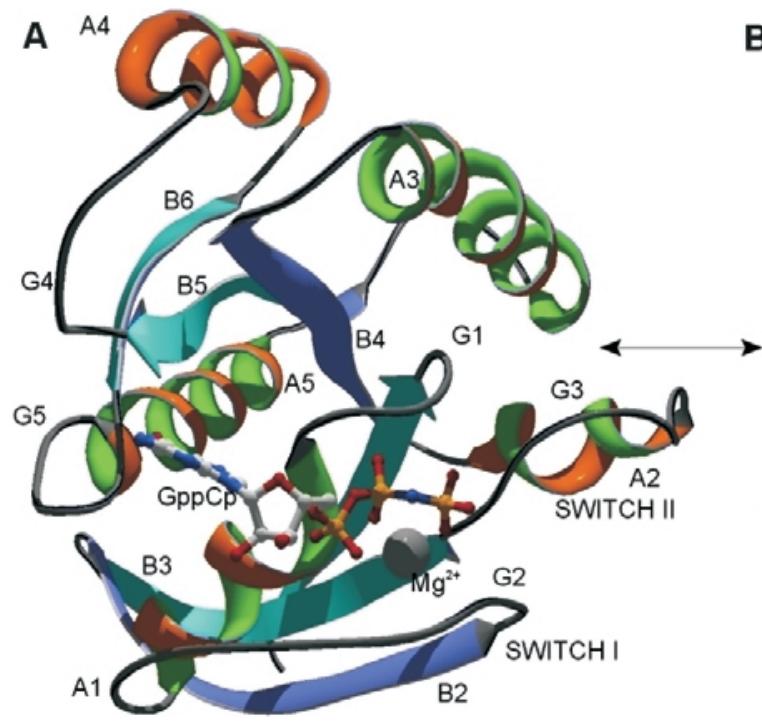

movement between Tyr32 in the G2 loop and phosphate groups [18]. The dynamics of switch I and II differs for GTP and GDP bound forms of Ras proteins [19, 20]. Rho, with its minimal catalytic apparatus, maintains the ability to hydrolyze GTP and convert the released free energy into a conformational

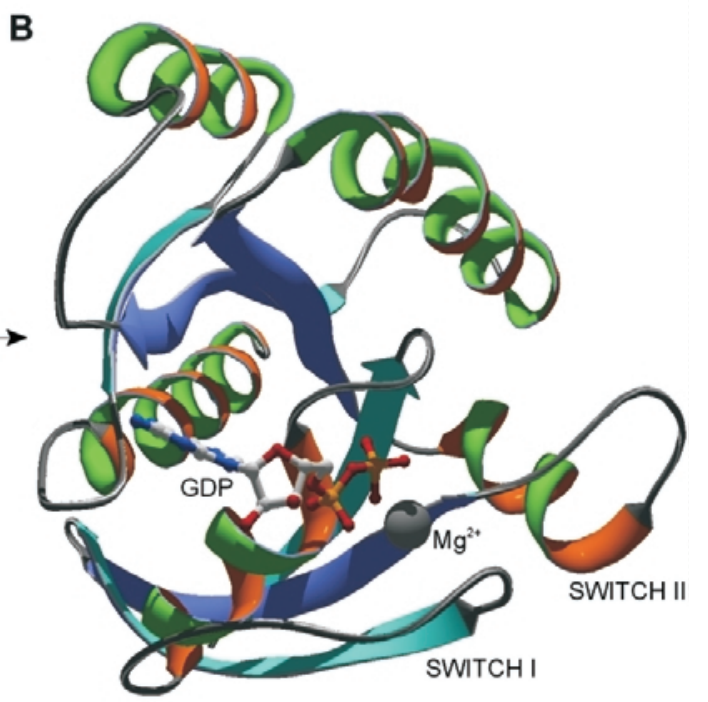

Figure 2. A schematic diagram of the G domain.

A. Ras $\cdot \mathrm{GppCp} \cdot \mathrm{Mg}^{2+}$ complex (PDB 5p21). Five $\alpha$-helices are marked A1-A5, six $\beta$-strands B1-B6 and five polypeptide loops G1-G5. B. Ras $\cdot G D P \cdot \mathrm{Mg}^{2+}$ complex (PDB 4q21). Conformational changes upon GTP hydrolysis can be observed in the switch I and switch II regions.

The dynamics of both switch regions has been examined using NMR, EPR and FTIR spectroscopy. The proposed "two state" movement of the effector loop was based on a clear change in effector regions. These changes are sufficient for the cycling between the effectorbound and effector-free form. The flexibility of the G1, G2, and G4 loops is defined as re- 
gional polysterism that is crucial for the functioning of small $\mathrm{G}$ proteins [21].

The differences in $G$ domain structure among small $G$ proteins mainly concern changes in the nucleotide binding region and structural elements including an additional $\mathrm{N}$-terminal $\alpha$-helix (present in Rho proteins) or an antiparallel $\beta$-sheet in the switch I and II region (found in Arf and Ran proteins) and differences in coordination of magnesium ion (present in Arf proteins). In Rac a 13 aminoacid insertion is present and forms an additional $\alpha$-helix. As an example of the differences in the switch II region, RhoA possesses an additional $\alpha$-helix [21]. An additional $\beta$-hairpin in Arf-1A is responsible for functionally relevant oligomerization, which is a rare phenomenon among $G$ proteins. Displacement of the consensus DXXG sequence in G2 loop by two additional amino acids decreases the ability of Arf proteins to hydrolyze GTP [22]. The A1 helix in Ran proteins forms two separate A1a and A1b helices [23]. Although these differences are significant, they do not change the overall $\mathrm{G}$ protein topology, as described [24].

In conclusion, a structural comparison of $\mathrm{G}$ proteins shows that the G1 phosphate recognition loop and the G4 nucleotide recognition loop are conserved, unlike the $\mathrm{G} 2 \mathrm{Mg}^{2+}$ coordination loop and the G3 $\gamma$-phosphate binding loop, which are more diverse. Conformational differences in the loops directly affect the ability of different $G$ proteins to bind a broad spectrum of effectors and the kinetics of GTP hydrolysis.

\section{GUANINE NUCLEOTIDE RECOGNITION - SPECIFICITY OF INTERACTION}

In all three-dimensional structures $G$ proteins are associated with $\mathrm{Mg}^{2+}$, which is essential for proper GTP/GDP binding as it coordinates oxygen atoms of the $\beta$ - and $\gamma$-phosphate

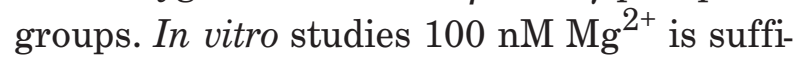
cient to ensure nucleotide binding. The influ- ence of $\mathrm{Mg}^{2+}$ on GDP binding is different for various small $\mathrm{G}$ proteins. $\mathrm{Mg}^{2+}$ binds to Ras with micromolar affinity and decreases the dissociation rate constant ( $k_{\text {off }}$ ) for GDP by four orders of magnitude [25]. The interaction between the $\gamma$-phosphate group and $\mathrm{Mg}^{2+}$ induces rigidity of switch I/II, in contrast, GTP hydrolysis destabilizes the effector region. Although the segments responsible for nucleotide binding are almost identical among $G$ proteins, the halftime of GTP/GDP exchange is different and varies from minutes to days. At present it is hard to rationalize these substantial kinetic differences.

Coordination of $\mathrm{Mg}^{2+}$ is mediated by a single water molecule and the conserved Asp residue from the G3 loop (Fig. 3). Alpha-helices surrounding the nucleotide binding site are similarly essential as well as four amides from the backbone chain of the G1 loop that form a hydrogen bonding network with oxygens of the $\alpha$ and $\beta$ phosphates. The weaker binding observed for GMP results from single (or at most double) hydrogen bond formation. The proper conformation of the G1 loop is accomplished by the presence of several glycines that adopt torsion angles forbidden for other amino acids (Fig. 3). The G1 loop is well ordered in all crystal structures and is not affected by GTP hydrolysis. In the majority of cases a single substitution of Gly for other residues in the G1 loop significantly lowers the ability of Ras to hydrolyze GTP. Mutations of Lys and Ser/Thr residues that are also present in the G1 loop affect mainly GTP/GDP binding, since the Lys side chain links $\alpha$ and $\beta$ phosphate groups, and the hydroxyl group of Ser (or Thr) governs coordination of $\mathrm{Mg}^{2+}$ (Fig. 3) [26, 27].

A $G$ protein in its free form (without the nucleotide) has a significantly decreased stability and determination of its affinity for nucleotide binding is inherently difficult. Therefore, nucleotide affinity is usually estimated according to $k_{\text {off }}$ values of the $\mathrm{G}$ protein complexed with a nucleotide. In Ras proteins the affinity is higher for GTP ( $k_{\text {off }}$ about $10^{-5}$ 


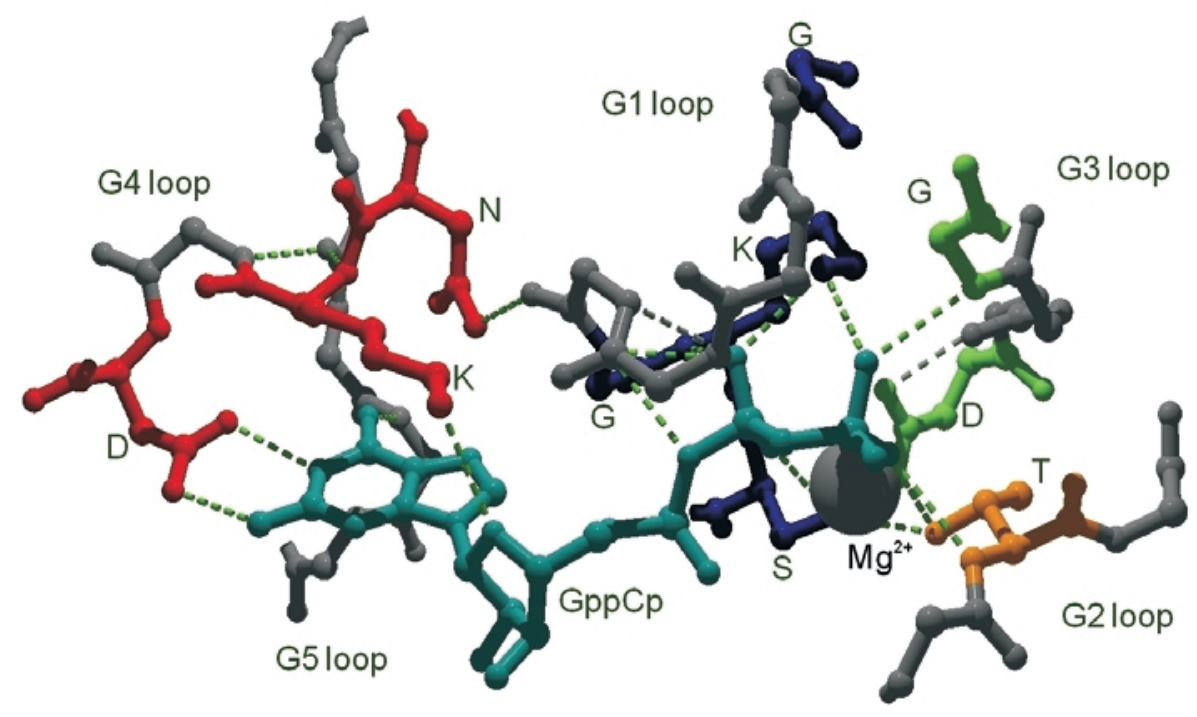

Figure 3. The guanine nucleotide binding site.

Ras $\cdot \mathrm{GppCp} \cdot \mathrm{Mg}^{2+}$ complex (PDB 5p21). Side chains of important residues are coloured and labeled with the one-letter amino-acid code.

$\mathrm{s}^{-1}$ ) than for GDP ( $k_{\text {off }}$ about $\left.10^{-4} \mathrm{~s}^{-1}\right)$ [28]. These data together with a rough estimate of the association rate constant $\left(k_{\text {on }}\right)$ for the free form of Ras provide an estimation of $K_{d}$ value at the level of $10^{-11} \mathrm{M}^{-1}$. The affinity for guanosine alone or for GMP is about six orders of magnitude lower than for GDP/GTP [29]. Binding of the nucleotide to Ras is associated with a local folding event of slow kinetics $[19,20]$. The $\mathrm{Mg}^{2+}$ and $\gamma$-phosphate binding is governed by the two most flexible elements of the G domain: the G2 (switch I) and G3 (switch II) loops. In the known complexes, $\mathrm{Mg}^{2+}$ is hexacoordinated to the $\beta$ - and $\gamma$-phosphate groups, to Ser (or Thr) from the G1 loop, to Thr from the G2 loop, and to two water molecules [27]. Additionally, the $\gamma$-phosphate of GTP forms a hydrogen bond with the Gly residue in the DXXG sequence of the G3 loop, and with the hydroxyl and amide of the Ser (Thr) residue in the G1 loop (Fig. 3). In Ras proteins an additional hydrogen bond is formed by Tyr32 hydroxyl and $\gamma$-phosphate [18].

Site-directed mutagenesis studies of the G domain showed that many amino-acid residues contribute to the affinity toward guanine nucleotides. These residues are located not only in the G1, G2 and G3 loops but also in a segments well outside the loop regions. Intramolecular interactions within the B1 and B2 loops and the A5 helix influence the stability of the G5 loop and are responsible for the affinity toward GDP [19, 20]. Upon GTP hydrolysis the structural elements that are responsible for binding of $\gamma$-phosphate and $\mathrm{Mg}^{2+}$ undergo dramatic changes. Coordination contacts of $\mathrm{Mg}^{2+}$ with the anion of the $\gamma$-phosphate and the hydroxyl of Ser (Thr) in the effector loop are lost. Also Gly of the G3 loop looses its contact with the $\gamma$-phosphate of the GTP. These lost contacts are replaced by an interaction of $\mathrm{Mg}^{2+}$ with water molecules. In some $\mathrm{G}$ proteins the interaction between an Asp residue from the G3 loop and $\mathrm{Mg}^{2+}$ is mediated by a water molecule. Disruption of this interaction during GTP hydrolysis decreases the affinity for $\mathrm{Mg}^{2+}$ in the GDP bound state. A lower affinity for $\mathrm{Mg}^{2+}$ is a permanent feature of Arf-1A, where five of seven coordination spheres are filled with water molecules [22].

The Asn and Asp residues from the NKXD sequence of the G4 loop participate in the hydrogen bonding with the guanine ring. The aliphatic part of the Lys side chain contacts 
the purine ring, whereas its $\varepsilon$-amino group forms a regular hydrogen bond with the endocyclic oxygen atom of the ribose (Fig. 3). The exocyclic keto oxygen in position 6 of the guanine ring is hydrogen bonded to one of the main-chain amides in the G5 loop. Loss of this interaction reduces the affinity by two to three orders of magnitude, thus providing strong discrimination against adenine nucleotides [30]. It is accomplished by the lack of favorable bonding of the Asp and Asn residues in NKXD to the adenine ring. Mutation of either of these residues drastically decreases the affinity for guanosine or switches the specificity with serious physiological consequences [31-33]. GTP binds better to G proteins than ATP by seven orders of magnitude. The purine ring stabilization mechanism varies among small $\mathrm{G}$ proteins. In the case of Ras, a Phe residue in close proximity to the G2 loop or amino acids from the G5 loop serve this function as well as hydrogen bonding between hydroxyl groups of ribose ring and main-chain carbonyl or side-chain carboxylate groups close to the G2 region [34].

\section{MECHANISM OF GTP HYDROLYSIS}

Small G proteins are very inefficient hydrolases with $k_{\text {cat }}$ in the range from $0.03 \mathrm{~min}^{-1}$ (for Ras) to $0.003 \mathrm{~min}^{-1}$ (for EF-Tu and Arf-1A), i.e. about $1 \%$ of an average reaction rate of heterotrimeric G proteins [2]. GTP hydrolysis proceeds according to the $\mathrm{S}_{\mathrm{N}} 2$ mechanism that stands for direct transfer of the GTP $\gamma$-phosphate group to $\mathrm{H}_{2} \mathrm{O}$ with inversion of configuration around the phosphate atom. The central role in catalysis is supposed to be played by a Gln residue from the G3 loop (Fig. 4). This residue acts as a catalytic base to activate a water molecule for the nucleophilic attack. In crystal structures the water molecule is located at the distance no longer than $4 \AA$ from the $\gamma$-phosphate group and is oriented for the nucleophilic attack due to hydrogen bonding with $\gamma$-phosphate and car- bonyl in the G2 loop (Fig. 4A) [35]. The crystal structures of the oncogenic Ras protein, which has a Gln to Glu mutation and is inactive, together with a positive effect on $k_{\text {cat }}$ of the reverse Glu to Gln mutation seem to confirm the model. Accordingly, Gln seems to be too weak base to accept a proton. However, the Gln residue is capable of stabilizing the pentavalent intermediate state in the hydrolysis reaction (Fig. 4B) [36]. The $\mathrm{pH}$ dependence of the enzyme activity reveals the presence of a functional group of $\mathrm{p} K_{\mathrm{a}}$ about 3 that is important in hydrolysis. The sharp transition in chemical shifts for the enzyme with bound ${ }^{31} \mathrm{P}$ points to the $\gamma$-phosphate group of GTP [37]. Indeed, exchange of $\mathrm{Mn}^{2+}$ for $\mathrm{Mg}^{2+}$ accelerates the hydrolysis rate via increasing the ability of $\gamma$-phosphate to accept the proton [38]. This type of reaction is described as substrate-assisted catalysis [39]. While the proton transfer step may not correspond to the kinetic activation barrier, it can be the rate limiting factor [40].

Based on a detailed theoretical analysis of crystal and NMR structures as well as LFER analysis of Ras mutants two models describing the intermediate state of GTP hydrolysis have been proposed (Fig. 4E). The dissociative model assumes that the first catalytic event is the disruption of the bond between $\beta$ - and $\gamma$-phosphate. In effect, an unstable metaphosphate intermediate is formed with a charge transition from $\beta$ - to $\gamma$-phosphate. The associative model assumes the presence of the pentavalent intermediate and accumulation of a negative charge on the $\gamma$-phosphate. This event is directly followed by the hydrolysis of the bond between $\beta$ and $\gamma$-phosphate with a charge transition to $\beta$-phosphate (Fig. 4C) [41]. GDP $\cdot \mathrm{Mg}^{2+} \cdot \mathrm{AlF}_{4}^{-}$(or $\mathrm{AlF}_{3} \mathrm{OH}^{-}$) complexes are stable transition state analogs that maintain the ability to interact with GAP. The geometry of the $\mathrm{AlF}_{4}{ }^{-}$complex is identical in the pentacoordinate intermediate state [35, 42]. Based on crystal structures of the analogs, the carboxyamide group of Gln (G3 loop) is able to polarize and orient the nucleophilic 


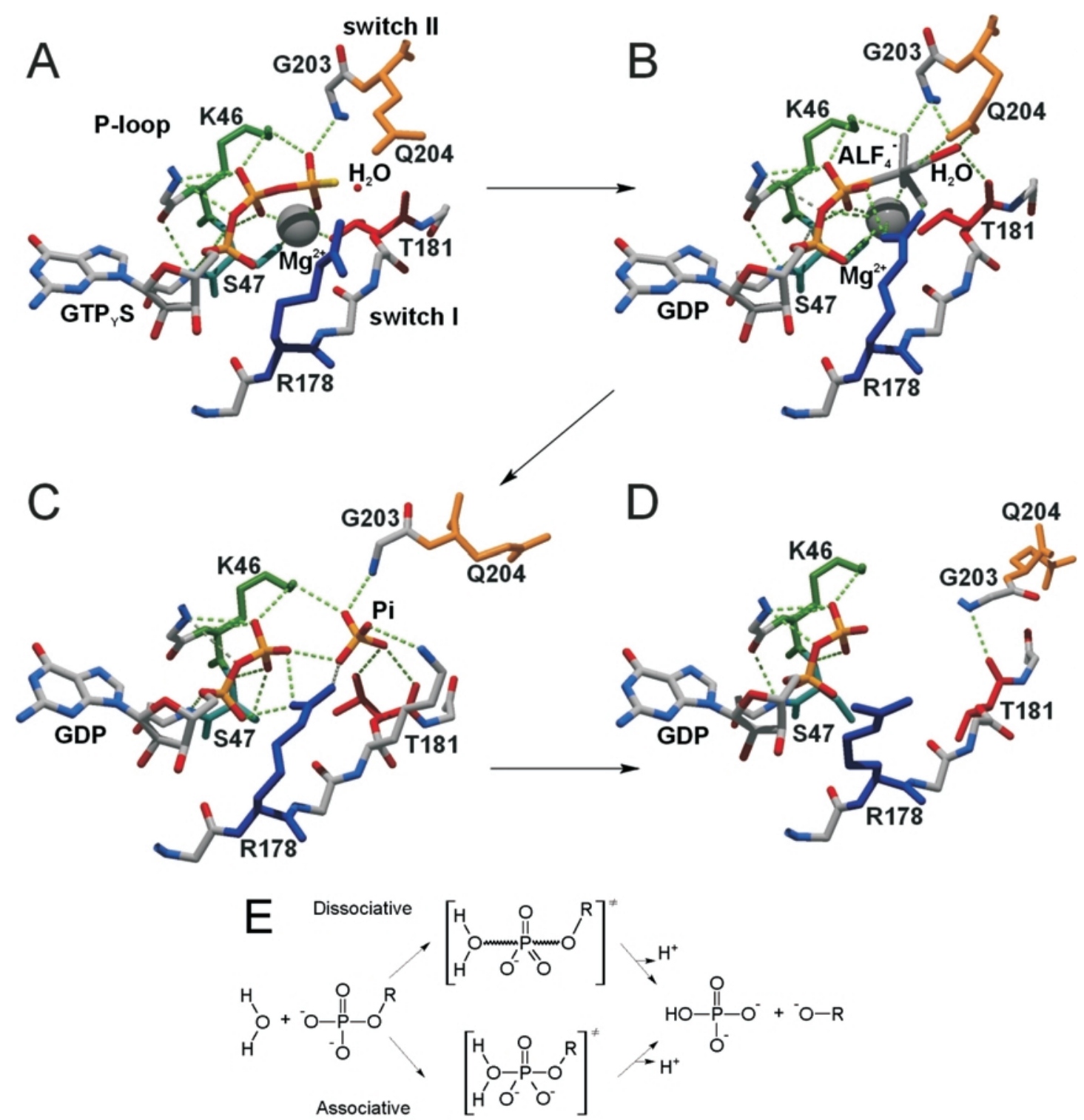

Figure 4. Mechanism of GTP hydrolysis, according to Berghuis et al. [35].

A. Gi $\alpha 1 \cdot \mathrm{GTP} \gamma \mathrm{S} \cdot \mathrm{Mg}^{2+}$ enzyme-substrate complex (PDB 1gia). A water molecule lies $3.8 \AA$ from the $\gamma$-phosphate and is positioned for a nucleophilic attack. R178 and Q204 do not contact GTP $\gamma \mathrm{S}$ [47]. B. $\mathrm{G}_{\mathrm{i} \alpha 1} \cdot \mathrm{GDP} \cdot \mathrm{AlF}_{4}{ }^{-} \cdot \mathrm{Mg}^{2+}$ pentacoordinate intermediate (PDB 1gfi). The $\mathrm{AlF}_{4}{ }^{-}$forms octahedral complex where the $\beta$-phosphate and a water molecule are placed in transaxial positions. R178 can form hydrogen bonds with the pentacoordinate intermediate and the oxygen bridging the phosphates. Such orientation of R178 supports both the associative and the dissociative models of GTP hydrolysis. Q204 and T181 are properly placed so that the attacking water molecule is polarized and well oriented [47]. C. $\mathrm{G}_{\mathrm{i} \alpha 1} \cdot \mathrm{GDP} \cdot \mathrm{Pi}$ enzyme-products complex (PDB 1git). Q204 (switch I) moves away and the $\mathrm{Mg}^{2+}$ coordination sphere is disrupted. R178 forms hydrogen bonds with $\beta$-phosphate and Pi. T181 as well as the preceding K180 (not marked) reorient and form hydrogen bonds with Pi, this causes a conformational change in switch I. The most affected region is switch II as a result of the escape of Q204 from the catalytic site [35]. D. Gi i $1^{\circ}$ GDP complex (PDB 1gg2). Switch II is disordered. Switch I moves away from the nucleotide because of the loss of the $\mathrm{Mg}^{2+}$ ligand. The catalytic site is disrupted [48]. E. Two models representing the transition state of the GTP hydrolysis reaction.

water molecule in the transition state for hydrolysis (Fig. 4B). In heterotrimeric G proteins an additional Arg in the G2 loop is pres- ent which stabilizes the developing negative charge on the released phosphate group (Fig. 4C). Proper orientation of the Gln and 
Arg residues is the reaction rate-limiting factor. Upon GDP $\cdot \mathrm{Mg}^{2+} \cdot \mathrm{AlF}_{4}{ }^{-}$binding these two residues are being correctly oriented and help to stabilize the intermediate state both in the associative and the dissociative model (Fig. 4B) [40]. The lack of the catalytic Arg residue in the small $\mathrm{G}$ protein family is mainly responsible for their low GTPase activity. The crucial Arg residue can be delivered by the GAP making hydrolysis much more efficient [43]. There is no known complex of the small G protein with $\mathrm{AlF}_{4}{ }^{-}$. The energy of $\mathrm{AlF}_{4}{ }^{-}$ binding is not sufficient for the formation of the metastable bipiramidal transition state analog due to a deficiency of the stabilizing helical domain or an Arg residue [44].

An analysis of FITR spectra along with computer aided calculations enabled a more detailed description of GTP hydrolysis. Upon GTP binding, reorientation of the Lys16, Gly15 and Val14 amides (P-loop) forces the flexible GTP molecule into a strained conformation [45]. The negative charge of $\gamma$-phosphate is then transferred to the $\beta$-phosphate group. The charge redistribution results in an electron structure resemblance of GTP to GDP and is the main factor decreasing the energy of transition activation barrier for the intermediate state of reaction [46].

\section{INTERACTION WITH EFFECTORS}

A large number of proteins is known to be regulated by small G proteins. The most important ones are depicted in Table 2. Small G proteins utilize GTP binding energy for stabilization of the two switch regions, which is needed for effector recognition. GTP hydrolysis causes a change in the favorable conformation and a mobility of the effector interacting region. The interaction energy of small G protein-effector/regulator promotes the transition to the intermediate state and speeds up the hydrolysis [50].

Binding of $\mathrm{GTP} \cdot \mathrm{Mg}^{2+}$ maintains the active conformation of the switch I and II regions $[19,20]$. The Gly residue in the DXXG sequence is essential for reorientation and local folding of this region. A Gly to Ala mutation blocks the GTP-induced conformational change and thus seriously decreases the effector affinity. Reorientation of the Tyr and Thr (ligands for $\mathrm{Mg}^{2+}$ ) that serve as the $\gamma$-phosphate binding residues occurs as a result of a conformational change in switch I. The changes within both switch regions are highly correlated [51]. The dynamic properties of the switch I region are important for effector binding. Removal of the Thr residue coordinating $\mathrm{Mg}^{2+}$ affects the dynamics as well as effector interaction and appears to be responsible for the conservation of this residue in GTP-binding proteins [17]. The region responsible in $\mathrm{G}$ proteins for effector binding has been studied by site-directed mutagenesis, for example a study of RIP/RalBP1 revealed the presence of residues responsible for the discrimination between Ras and Ral effectors [52]. One of the proteins regulated by Ras is the Ser/Thr kinase Raf-1 which in turn interacts with MEKK in the MAP kinases pathway. Raf- 1 contains an 80 amino-acid Ras binding domain (RBD) that binds to Ras and Rap-1A with $K_{\mathrm{d}}=20 \mathrm{nM}$ in a GTP dependent manner [53]. Rap-1A is a homolog of Ras that

Table 2. Selected effectors of the Rho/Cdc42/Rac family, according to Bourne et al. [1] and Aspenstrom [49].

\begin{tabular}{ll}
\hline \multirow{2}{*}{ Rho } & PI3-kinase, PI4,5-kinase, phospholipase D, rhophilin, kinectin, rhotekin, DGK\}, PKN, MBS, \\
& ROK/ROCK/Rho kinase, Bni1, Bnr1, Pkc1, p140mDia, Fks1, Fks2 \\
\hline \multirow{2}{*}{ Cdc42 } & NADPH oxidase, PI3-kinase, PI4,5-kinase, DGK, PAK, POSH, IQGAP, MLK2, MLK3, \\
\hline \multirow{2}{*}{ Rac } & POR1, Sra-1, S6-kinase \\
\hline
\end{tabular}


activates MAP kinases. The effector loop and the B2 and B3 strands form the kinase Raf-1 recognition site [54]. RBD possesses a typical ubiquitin fold. The $\beta$-strands B2 in RBD and B2 in Rap-1 form an antiparallel $\beta$-sheet that directly serves as an interaction site (Fig. 5A). Formation of an intermolecular $\beta$-sheet is a common mechanism for all known RBDs [55, 56]. Additionally, the C-terminal Arg residue of the A1 helix in RBD is crucial for small $G$ protein binding. Interestingly, switch II and other GTP recognition residues in Rap-1A do not take part in the interaction with RBDRaf-1 [57]. In RBDRap-1A complex switch II is solvent exposed and is able to bind a modulator gamma catalytic domain and a change in conformation of the effector may represent an allosteric component of the activation (Fig. 5B) [56].

Modifiers of the interaction of $\mathrm{G}$ proteins with effectors are also known. A protein named 14-3-3 seems to interact with the Raf-1 kinase and supports Ras in its activation [59]. Another protein that helps Ras in transducing the signal to its effectors is KSR (kinase suppressor of Ras) [60]. This modifier facilitates signal transmission between Raf, MAP and MAP kinase [61]. The CNK protein (connector enhancer of KSR) possesses several protein-protein interaction domains (SAM, PDZ,
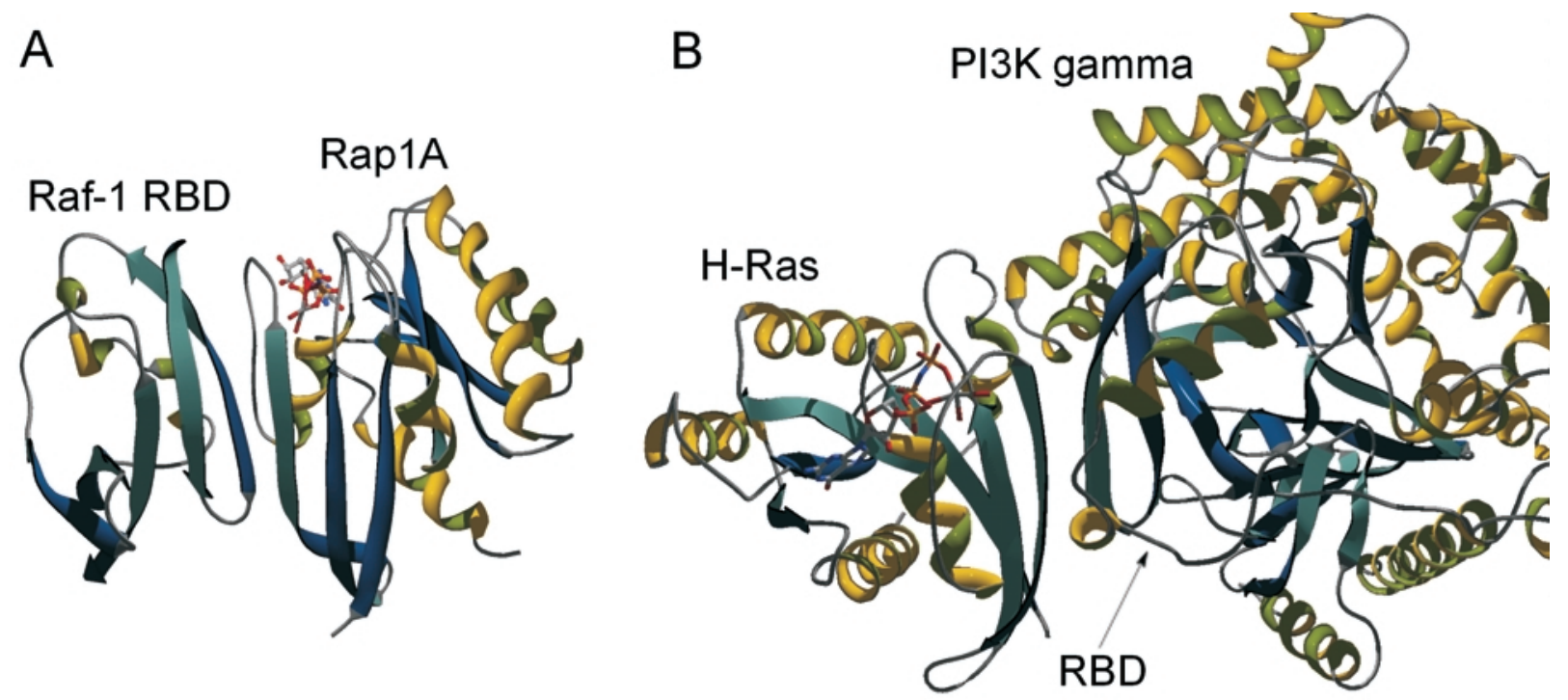

Figure 5. Interaction of small G proteins with effectors.

The RBD domains form intermolecular $\beta$-sheets with the switch I region at the interaction site. A. Raf1RBD·GppNHp · Rap1A complex (PDB 1gua). B. H-Ras · PI3K gamma complex. (PDB 1he8).

protein such as RasGAP. Binding of RasGAP to Raf- $1 \cdot \operatorname{Ras} \cdot \mathrm{GTP} \cdot \mathrm{Mg}^{2+}$ induces GTP hydrolysis followed by a release of Raf- 1 from the complex. The $\mathrm{Zn}^{2+}$ binding cysteine-rich domain (CRD) forms a second site of Ras binding in Raf-1 [58]. RBD domains can also be found in the group of small $\mathrm{G}$ protein modulators such as RalGEF [55].

A loop in the RBD domain of phosphoinositide 3-kinase gamma (PI3K gamma) positions Ras so that it uses both the switch I and switch II regions to interact with the effector. Ras also forms a direct contact with the PI3K
$\mathrm{PH}$ and proline rich region) and acts upstream of Raf modifying signal propagation [62].

\section{MOLECULAR SWITCHES AND THE ACTIVATION-INACTIVATION CYCLE}

The signaling pathways mediated by small $\mathrm{G}$ proteins are widely recognized as responsible for regulation of many processes in eukaryotic cells. Many membrane receptors and up- 
stream regulators are known that activate these pathways [63]. The outstanding diversity of cellular targets that can interact with small G proteins has recently been reviewed [64]. It is also known that there is cooperativity and coactivation among various members of the small $G$ protein superfamily and their regulators. For example, the cross-talk between Ras and Rho proteins involves two classes of regulatory mechanisms. One of them is signal divergence, in which a signal from one receptor activates two different types of GEFs: Ras GEF and Rho GEF. Alternatively, there is a common GEF protein, which is able to activate both the Ras and Rho proteins. Signal convergence is an outcome of activation of one effector molecule by two different small $G$ proteins resulting in a single cellular response [65].

Low GTPase activity and GDP dissociation rate are of ultimate physiological importance since they enable precise positive and negative regulation of small $\mathrm{G}$ proteins (Fig. 6). This regulation is mainly accomplished by GTPase dissociation inhibitors (GDI), GTPase activating proteins (GAP) and guanine nucleotide exchange factor proteins (GEF). In the active, GTP-bound state, GTPases interact with target proteins to promote a cellular response. GEF catalyzes the exchange of GTP for bound GDP. The low intrinsic GTPase activity is stimulated by GAP and completes the cycle. Additional regulation is provided by GDI that keeps the G protein in the GDPbound, inactive, state (Fig. 6).

\section{GDI}

GDI proteins bind to a variety of proteins that are postranslationally modified by addition of the geranylgeranyl moiety. GDIs are able to extract these proteins from the cellular membrane and create their cytosolic pool. Cytosolic G proteins occur mainly in the GDI-bound form in the cell. The role of GDI in partitioning $G$ proteins between the mem-

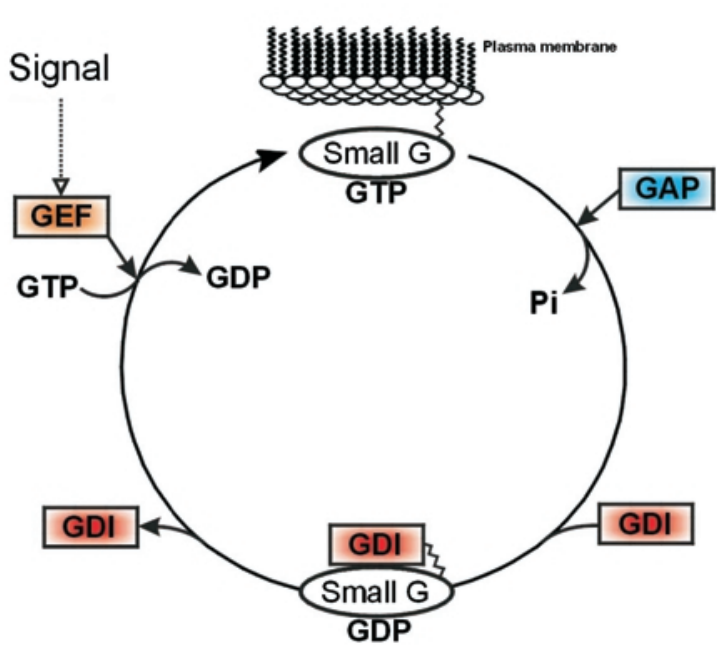

Figure 6. Mode of activation of small G protein superfamily.

GAPs stimulate the low GTPase activity to promote the conversion of the GTP-bound to the GDP-bound form. GDIs affect dissociation of GDP and maintain the GTPases in their inactive state. GEFs after receiving the signal catalyze the exchange of GTP for GDP.

brane and the cytosol seems to be physiologically more important than the inhibition of nucleotide dissociation itself.

Up to date, two types of GDI proteins have been described: RabGDI and RhoGDI (Fig. 7). Interestingly, even though there is no structural similarity between RhoGDI and RabGDI, they perform the same function in different families of small $G$ proteins. RabGDI regulates membrane association and recycling of the Rab family of small G proteins, which are critical in vesicle-membrane trafficking. The $50 \mathrm{kDa} \alpha$ isoform of RabGDI is built of two domains: the larger $\beta$ domain, composed of seven antiparallel and seven parallel $\beta$-strands, and the smaller $\alpha$ helical domain. The smaller domain is structurally similar to monooxygenases and flavine oxidases. The $\beta$ domain of RabGDI contains the Rab binding GCD domain and a conserved region that are both responsible for the interaction with geranylgeranyltransferase II. The GCD domain is similar to the Rep protein which transports Rab to geranylgeranyltransferase II (Fig. 7C) [66]. 


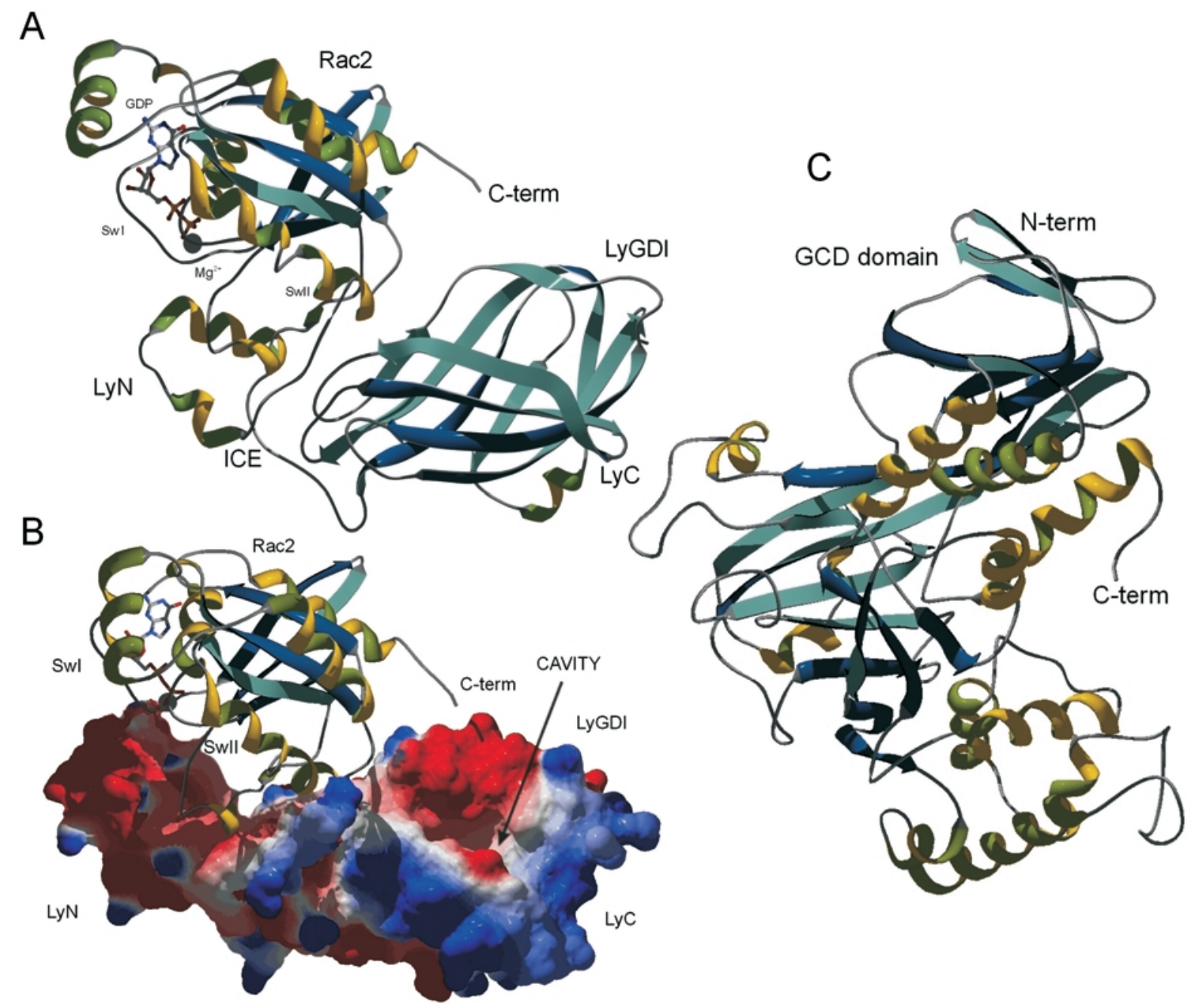

Figure 7. Guanine nucleotide dissociation inhibitors.

A. Rac2 $\cdot$ RhoGDI (LyGDI) complex (PDB 1ds6). C-terminal immunoglobulin-like domain is designated LyC, and N-terminal, LyN; linker recognized by ICE protease, ICE. B. Surface and electrostatic potential of LyGDI. Positively charged (basic) regions in blue and negatively charged (acidic) ones in red. The hydrophobic cavity responsible for binding of the C-terminally attached isoprenyl moiety is also shown. The switch I (SwI) and switch II (SwII) regions are buried in the interaction site. C. RabGDI (PDB 1gnd). The GCD domain responsible for Rab binding is shown.

RhoGDI is composed of 204 amino-acid residues and contains two domains: a C-terminal $16 \mathrm{kDa}$ domain that strongly binds the small $\mathrm{G}$ protein through its C-terminal Cys-attached lipid moiety and an N-terminal domain, responsible for switch region binding and nucleotide exchange inhibition (Fig. 7A) [67, 68]. The C-terminal domain possesses an immunoglobulin-like type $\mathbf{S}$ fold which seldom occurs in cytosolic proteins. The structure is built of nine $\beta$-strands (antiparallel $\beta$-sandwich with a Greek key topology) and a single 310 -helix. The domain is highly protease resistant and contains a large and deep $(12 \times 8 \times 10 \AA)$ isoprene-specific hydrophobic cavity (Fig. 8B) [68-70]. Docking of the lipid moiety depends on the presence of an Asp residue in a close proximity to the hydrophobic cavity. Excluding the C-terminus, only a small part of the Rho molecule contacts GDI [71]. In RhoA switch II and a fragment of the A3 helix form the contact interface. The N-terminal domain in free RhoGDI is basically unstructured and sensitive to proteolysis. It has been shown that this domain can be proteolytically cleaved by cysteine proteinases that belong to 


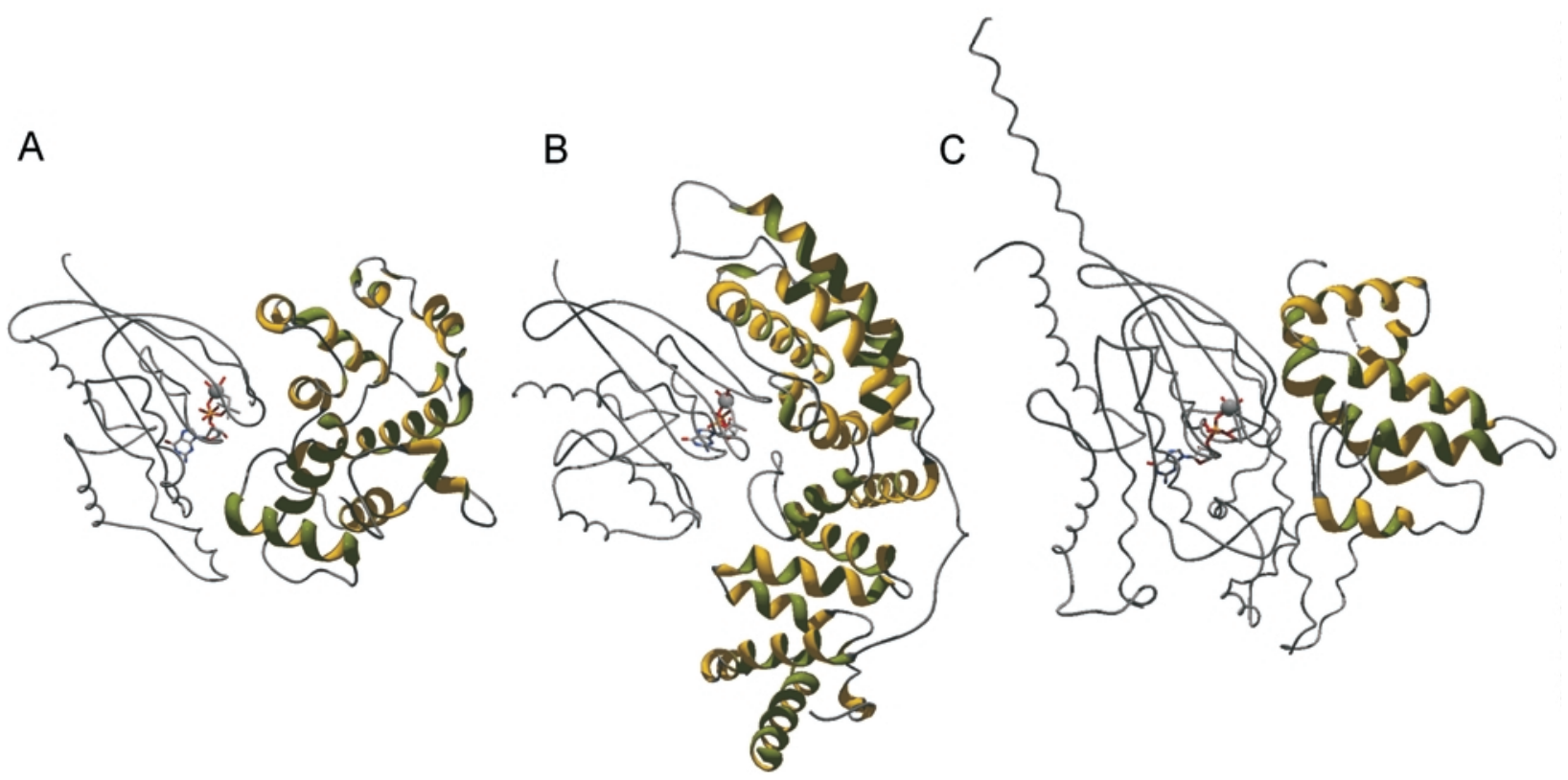

Figure 8. GTPase activating proteins.

GAPs (coloured helices on the right) complexed with $\mathrm{G}$ proteins (C $\alpha$-worm in gray). A Rho $\cdot \mathrm{GDP} \cdot \mathrm{AlF}_{4}{ }^{-} \cdot \mathrm{RhoGAP}$ (PDB 1tx4). B. H-Ras·GDP ·p120GAP (PDB 1wq1). C. $\mathrm{G}_{\mathrm{i} \alpha 1} \cdot \mathrm{GDP} \cdot \mathrm{AlF}_{4}{ }^{-} \cdot \mathrm{RGS4}$ (PDB 1agr).

the ICE/CED-3 family (Fig. 7B). Hydrolysis of the N-terminal LyGDI (a homolog of RhoGDI) domain by IL- $1 \beta$-convertase (ICE) leads to the inactivation of LyGDI and, therefore, is involved in the regulation of inflammatory processes and apoptosis [72]. The N-terminal, disordered, fragment becomes structured upon Rho binding and provides more than $60 \%$ of the total Rac $\cdot$ RhoGDI interface making thus a major contribution to the complex binding energy. Upon RhoGDI binding to Rho a helical hairpin structure is formed that obscures switch I and II [68]. The masking of the effector region directly prohibits effector binding. In the complex, the conformation of switch II precludes GTP hydrolysis independently of GAP presence, and the conformation of switch I abolishes nucleotide exchange. Additionally, the Thr residue that coordinates $\mathrm{Mg}^{2+}$ efficiently blocks GEF catalyzed nucleotide exchange. In the Rho family the surface epitope that binds the N-terminus of RhoGDI is highly conserved [70]. Two-step kinetics is observed for Rho/RhoGDI binding. In the first step a reorientation of the Rho molecule by the N-terminal domain of GDI increases the accessibility of the geranylgeranyl group to RhoGDI, followed by the step of the geranylgeranyl moiety extraction from the membrane by the C-terminal domain of GDI [67, $73]$.

\section{GAP}

GAP proteins accelerate the rate of GTP hydrolysis by four to eight orders of magnitude. Only a small part of the GAP family has probably been recognized and the known members include p50, p120, p130, p85, myr5, Bcr, Graf, chimerin, and Abr. Mutational analysis of Ras has shown that the switch regions I and II are responsible for the interaction of $\mathrm{G}$ proteins with GAP. The interaction forces a conformational change that rigidifies the $\mathrm{G}$ domain and promotes a transition towards the $\gamma$-phosphate pentacovalent intermediate state of the hydrolytic reaction [26]. The acceleration of GTP hydrolysis is possible thanks to the catalytic Arg residue supplied by the GAP molecule (Fig. 9) [74, 75]. GAPs are predominantly $\alpha$-helical proteins and sometimes contain a 


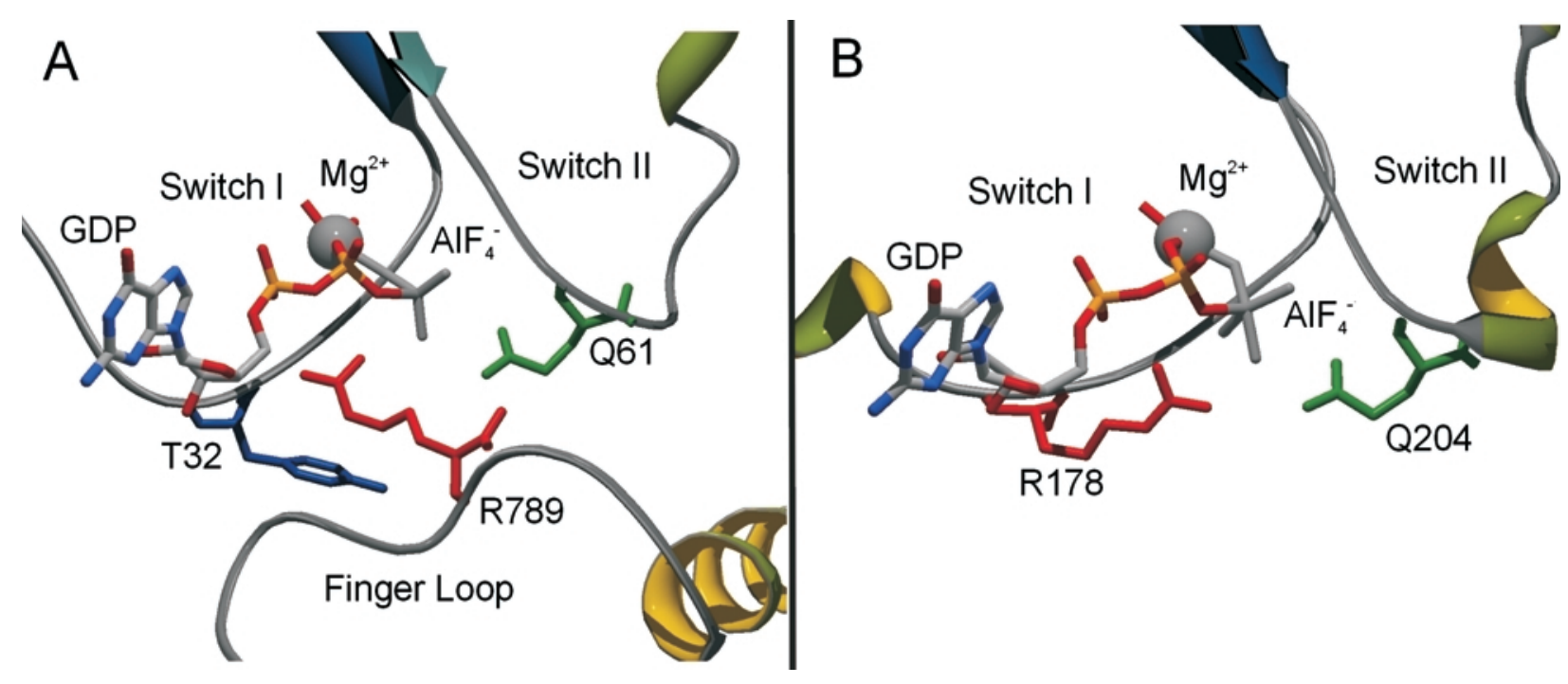

Figure 9. Arginine finger.

A. Structure of H-Ras · GDP·p120GAP (PDB 1wq1). p120GAP participates in GTP hydrolysis by insertion of catalytic R789 (red) present in the finger loop. Catalytic Q61 (green) (corresponding to Q204 in $\mathrm{G}_{\mathrm{i} \alpha 1}$ ) is well oriented in the interaction of switches I and II with p120GAP. B. Structure of $\mathrm{G}_{\mathrm{i} \alpha 1} \cdot \mathrm{GDP} \cdot \mathrm{AlF}_{4}{ }^{-}$(PDB $1 \mathrm{gfi}$ ). R178 (red) from switch I directly participates in GTP hydrolysis.

four-helix bundle motif (Fig. 8) [76, 77]. Additionally they contain flexible regions that can undergo conformation changes upon binding to GTPases [74, 76]. The C-terminal domain of Bcr $(\mathrm{BH})$ has a number of conservative residues along a shallow groove formed by two helices that are responsible for the interaction with the GTPase [78].

Proteins with GAP activity often contain other domains that are characteristic for cellular signaling processes, such as $\mathrm{SH} 2$, SH3, $\mathrm{PH}$, and proline-rich regions [79]. The $\alpha$ subunits of heterotrimeric $\mathrm{G}$ proteins also possess their own regulatory proteins, called RGS, with a GAP activity. RGS proteins accelerate about 100 times the rate of GTP hydrolysis. Unlike GAPs, RGSs only stabilize the GTPase domain since the catalytic Arg residue is present in the catalytic domain [42]. RGS-like domains are often found in other types of GTPase regulators.

Based on the structural data of small G proteins and their activating regulator complexes, a mechanism of GAPs action has been proposed. A catalytic Arg residue is located in a loop region of GAP and forms an arginine-finger motif (Fig. 9) [26]. The arginine finger helps align a water molecule for nuclephilic attack together with the catalytic Gln [43]. Association of GAP with the G domain leads to the rigidifying of the switch regions and to entropic stabilization of the intermediate state of the reaction [80]. Catalytic residues are oriented and stabilized in a way that accelarates GTP hydrolysis. Binding of GAP also stabilizes the residues responsible for $\mathrm{Mg}^{2+}$ coordination and thus additionally rigidifies the interaction of small $G$ protein and GTP [74].

\section{GEF}

In addition to inefficient catalysis, small $\mathrm{G}$ proteins are not capable of efficient GDP dissociation. GEF proteins accelerate GDP/GTP exchange in small $\mathrm{G}$ proteins as a response to the extracellular signal. Among the already known GEFs are: Dbl, Vav1, Dbs, Lbc, Lfc, Lsc, Vav2, p115RhoGEF, PDZ-RhoGEF, Tiam1, FGD1, frabin, Rcc1, cytohesin1, Sec7, Gea2p, SOS, Trio, Pix, Mss4, p140RasGRF, and C3G [3]. Chosen GEF structures are shown in Fig. 10. Typically, GEFs are large, 


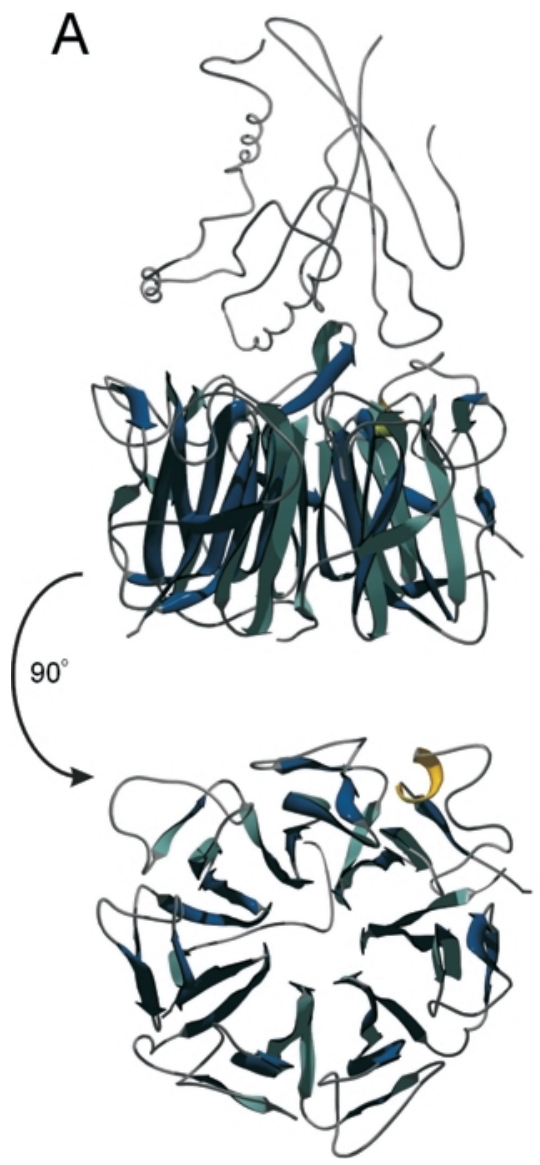

B
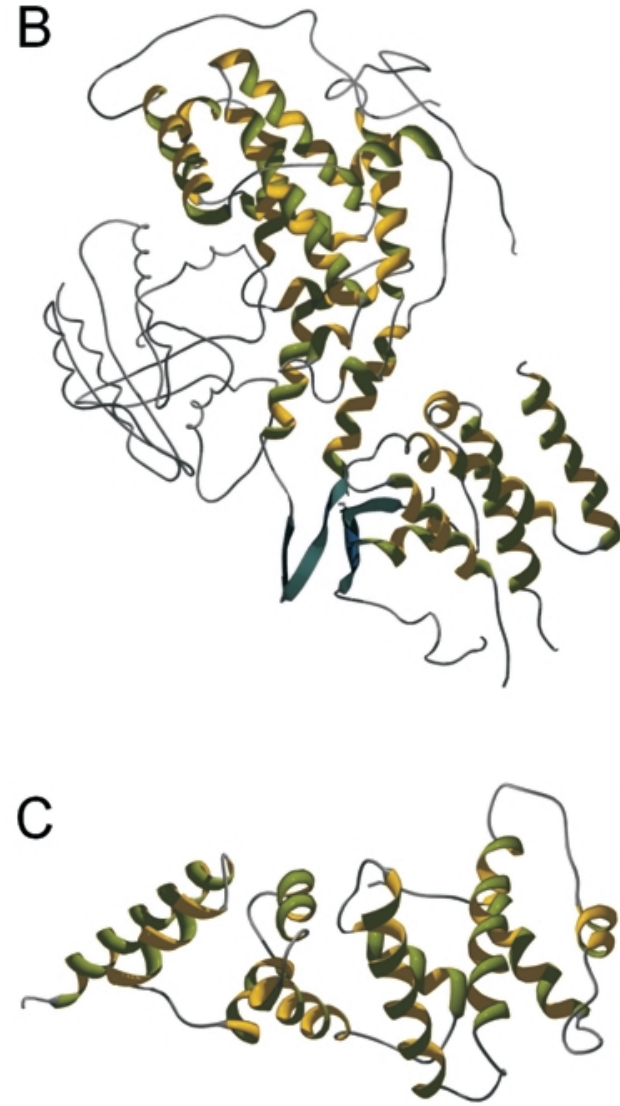

Figure 10. Guanine nucleotide exchange factor.

A. Rcc1 Ran complex (PDB 1i2m). Rcc1 shown in colour as a seven-bladed $\beta$ propeler [81]. B. The Cdc25 domain of SOS-1 complexed with H-Ras (in gray) (PDB 1bkd) [82]. C. The Sec7 domain of ARNO an exchange factor for Arf (PDB 1pbv) [83].

multidomain proteins that consist of a catalytic domain composed of 200-300 aminoacid residues and flanked by other domains responsible for oligomerization, protein-protein and protein-lipid interactions. GEF associated domains include: a tandem of DH-PH domains (Dbl homology - pleckstrin homology), SH2, SH3 (Src homology 2, 3), RGSL (regulators of $\mathrm{G}$ protein signaling-like), also known as LH (Lsc homology), PDZ, SAM (sterile alpha motif), IQ, C2, CH (calponin homology), proline-rich, and rubredoxin domain (two CXXC $\mathrm{Zn}^{2+}$ coordinating sequences) [3, 84]. SH2 domains are responsible for phosphotyrosine recognition, whereas SH3 recognize proline-rich regions. Both serve as protein-protein interaction adapters. The IQ motif, present in p140RasGRF, is regulated by calmodulin complexed with $\mathrm{Ca}^{2+}$.
The RGSL domain (p115RhoGEF) stimulates GTPase activity in $\mathrm{G}_{\alpha 12}$ and $\mathrm{G}_{\alpha 13}$ and in this way p115RhoGEF acts as a modulator of $G_{\alpha}$ regulation of Rho [85-87].

GEF proteins of small $G$ proteins accelerate dissociation of bound GDP and promote the formation of the GTP-bound state. Some GEFs have catalytic activity only towards a single GTPase (for example, FGDI to Cdc42, UNC-73B to Rac), while others act on a panel of targets (Dbl and Ost both activate Cdc42 and Rho) [88-91]. In nearly all cases the catalytic DH domain is arranged in tandem with the about 100 amino acid large $\mathrm{PH}$ domain (Fig. 11). The latter domain is a widely distributed signaling module involved in intracellular membrane targeting [92, 93]. It has been suggested that in signaling pathways an interaction through a $\mathrm{PH}$ domain could acti- 


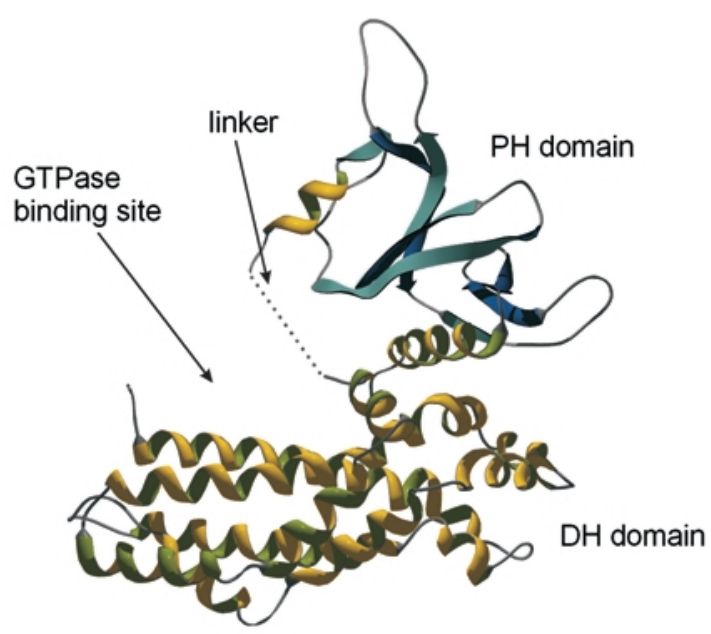

Figure 11. Structure of the DH and PH domains.

Structure of two domains from the human SOS-1 protein (PDB 1dbh). The linker segment and the GTPase binding site are indicated.

vate GEFs by recruiting them to membranes, where prenylated small $\mathrm{G}$ proteins are located [94, 95]. However, it is also possible that the $\mathrm{PH}$ domain fulfils a more specific role in regulating GEF activity by providing catalytic residues, contributing to the GEF/G protein binding, allosterically modulating the catalytic activity or recruiting additional regulatory factors (for example, PtdIns(3,4) $\mathrm{P}_{2}$ ) [96].

The $\mathrm{DH}$ domain of SOS is of predominantly helical structure and comprises 11 helical segments that form a bundle. Three of these helical segments are interrupted by kinks and three other conserved long helices pack together to form a core of the $\mathrm{DH}$ domain (Fig. 11) [97]. A typical PH domain fold consists of seven $\beta$-strands forming a $\beta$-sandwich flanked at one end by a C-terminal $\alpha$-helix. Most PH domains contain a phosphatidylinositol lipids binding site [98]. The DH and $\mathrm{PH}$ domains are joined by a 13-residue interdomain linker. The interaction between $\mathrm{DH}$ and $\mathrm{PH}$ occurs mainly via helices, forming a tight interface. Interestingly, the regions of both domains that form the interface are weakly conserved (Fig. 11) [97].

Based on the crystal structure of the SOS · GDP · Ras complex (Fig. 10B) [97], there are two ways of GEF-catalyzed dissociation of GDP: stabilization of the nucleotide-free form of $\mathrm{G}$ protein and disruption of the GDP binding site [99]. In the complex, switch I, II and P-loop regions of Ras are in the contact area with SOS. The main interaction site is formed by the switch II region that undergoes a conformational change upon complex formation. The switch I region is weakly ordered in Ras.GDP and is replaced by a helical hairpin of SOS in the complex. Glu942 and Leu939 of SOS protrude to the $\gamma$-phosphate and $\mathrm{Mg}^{2+}$ binding site. The Glu residue interacts with Ser within the P-loop and destroys contacts between phosphate binding loop and the $\beta$-phosphate group of GDP. Leu939 abolishes $\mathrm{Mg}^{2+}$ coordination sphere and thus decreases the affinity to GDP. Such structural distortion moves the P-loop to the position that makes nucleotide binding impossible. Generally, the interaction area between GEF and small G protein is large in order to stabilize the transient but otherwise unstable nucleotide-free form of the $\mathrm{G}$ protein. The $\mathrm{G}$ domain without the bound nucleotide is solvent exposed and capable of accepting a GTP molecule and GEF dissociation. This step limits the rate of nucleotide exchange [99, 100].

We thank Dr. Zygmunt Derewenda for helpful discussions.

\section{R E F E R E N C E S}

1. Bourne, H.R., Sanders, D.A. \& McCormick, F. (1990) The GTPase superfamily: A conserved switch for diverse cell functions. Nature 348, 125-132.

2. Bourne, H.R., Sanders, D.A. \& McCormick, F. (1991) The GTPase superfamily: A conserved structure and molecular mechanism. Nature 349, 117-127.

3. Takai, Y., Sasaki, T. \& Matozaki, T. (2001) Small GTP-binding proteins. Physiol Rev. 81, 153-208. 
4. Valencia, A., Chardin, P., Wittinghofer, A. \& Sander, C. (1991) The ras protein family: Evolutionary tree and role of conserved amino acids. Biochemistry 30, 4637-4648.

5. Casey, P.J., Solski, P.A., Der, C.J. \& Buss, J.E. (1989) p21ras is modified by a farnesyl isopre noid. Proc. Natl. Acad. Sci. U.S.A. 86, 8323-8327.

6. Fujiyama, A. \& Tamanoi, F. (1990) RAS2 protein of Saccharomyces cerevisiae undergoes removal of methionine at $\mathrm{N}$ terminus and removal of three amino acids at $\mathrm{C}$ terminus. J. Biol. Chem. 265, 3362-3368.

7. Gutierrez, L., Magee, A.I., Marshall, C.J. \& Hancock, J.F. (1989) Post-translational processing of p21ras is two-step and involves carboxyl-methylation and carboxy-terminal proteolysis. EMBO J. 8, 1093-1098.

8. Schafer, W.R., Kim, R., Sterne, R., Thorner, J., Kim, S.H. \& Rine, J. (1989) Genetic and pharmacological suppression of oncogenic mutations in ras genes of yeast and humans. Science 245, 379-385.

9. Hancock, J.F., Magee, A.I., Childs, J.E. \& Marshall, C.J. (1989) All ras proteins are polyisoprenylated but only some are palmitoylated. Cell 57, 1167-1177.

10. Kohl, N.E., Omer, C.A., Conner, M.W., Anthony, N.J., Davide, J.P., deSolms, S.J., Giuliani, E.A., Gomez, R.P., Graham, S.L., Hamilton, K. et al. (1995) Inhibition of farnesyltransferase induces regression of mammary and salivary carcinomas in ras transgenic mice. Nat. Med. 1, 792-797.

11. Dever, T.E., Glynias, M.J. \& Merrick, W.C. (1987) GTP-binding domain: Three consensus sequence elements with distinct spacing. Proc. Natl. Acad. Sci. U.S.A. 84, 1814-1818.

12. Jurnak, F. (1985) Structure of the GDP domain of EF-Tu and location of the amino acids homologous to ras oncogene proteins. Science 230, 32-36.
13. la Cour, T.F., Nyborg, J., Thirup, S. \& Clark, B.F. (1985) Structural details of the binding of guanosine diphosphate to elongation factor $\mathrm{Tu}$ from $E$. coli as studied by X-ray crystallography. EMBO J. 4, 2385-2388.

14. Gilman, A.G. (1987) G proteins: Transducers of receptor-generated signals. Annu. Rev. Biochem. 56, 615-649.

15. Walker, J.E., Saraste, M., Runswick, M.J. \& Gay, N.J. (1982) Distantly related sequences in the alpha- and beta-subunits of ATP synthase, myosin, kinases and other ATP-requiring enzymes and a common nucleotide binding fold. EMBO J. 1, 945-951.

16. Sprang, S.R. (1997) G protein mechanisms: Insights from structural analysis. Annu. Rev. Biochem. 66, 639-678.

17. Spoerner, M., Herrmann, C., Vetter, I.R., Kalbitzer, H.R. \& Wittinghofer, A. (2001) Dynamic properties of the Ras switch I region and its importance for binding to effectors. Proc. Natl. Acad. Sci. U.S.A. 98, 4944-4949.

18. Geyer, M., Schweins, T., Herrmann, C., Prisner, T., Wittinghofer, A. \& Kalbitzer, H.R. (1996) Conformational transitions in p21ras and in its complexes with the effector protein Raf-RBD and the GTPase activating protein GAP. Biochemistry 35, 10308-10320.

19. Zhang, J. \& Matthews, C.R. (1998) The role of ligand binding in the kinetic folding mechanism of human p21(H-ras) protein. Biochemistry 37, 14891-14899.

20.Zhang, J. \& Matthews, C.R. (1998) Ligand binding is the principal determinant of stability for the $\mathrm{p} 21(\mathrm{H})$-ras protein. Biochemistry 37 , 14881-14890.

21. Ihara, K., Muraguchi, S., Kato, M., Shimizu, T., Shirakawa, M., Kuroda, S., Kaibuchi, K. \& Hakoshima, T. (1998) Crystal structure of human RhoA in a dominantly active form complexed with a GTP analogue. J. Biol. Chem. 273, 9656-9666. 
22.Amor, J.C., Harrison, D.H., Kahn, R.A. \& Ringe, D. (1994) Structure of the human ADP-ribosylation factor 1 complexed with GDP. Nature 372, 704-708.

23. Scheffzek, K., Klebe, C., Fritz-Wolf, K., Kabsch, W. \& Wittinghofer, A. (1995) Crystal structure of the nuclear Ras-related protein Ran in its GDP-bound form. Nature 374, 378-381.

24. Kjeldgaard, M., Nyborg, J. \& Clark, B.F.C. (1996) The GTP binding motif: Variations on a theme. FASEB J. 10, 1347-1368.

25. John, J., Rensland, H., Schlichting, I., Vetter, I., Borasio, G.D., Goody, R.S. \& Wittinghofer, A. (1993) Kinetic and structural analysis of the $\mathrm{Mg}^{(2+)}$-binding site of the guanine nucleotide-binding protein p21H-ras. J. Biol. Chem. 268, 923-929.

26. Scheffzek, K., Ahmadian, M.R., Kabsch, W., Wiesmüller, L., Lautwein, A., Schmitz, F. \& Wittinghofer, A. (1997) The Ras-RasGAP complex: Structural basis for GTPase activation and its loss in oncogenic Ras mutants. Science 277, 333-338.

27. Wei, Y., Zhang, Y., Liu, X., Minor, W., Nakamoto, R.K., Somlyo, A.V., Somlyo, A.P. \& Derewenda, Z.S. (1997) Crystal structure of RhoA-GDP and its functional implications. Nat. Struct. Biol. 4, 699-703.

28. Feuerstein, J., Kalbitzer, H.R., John, J., Goody, R.S. \& Wittinghofer, A. (1987) Characterisation of the metal-ion-GDP complex at the active sites of transforming and nontransforming p21 proteins by observation of the ${ }^{17} \mathrm{O}-\mathrm{Mn}$ superhyperfine coupling and by kinetic methods. Eur. J. Biochem. 162, 49-55.

29. John, J., Sohmen, R., Feuerstein, J., Linke, R., Wittinghofer, A. \& Goody, R.S. (1990) Kinetics of interaction of nucleotides with nucleotide-free H-ras p21. Biochemistry 29, 6058-6065.

30.Denker, B.M., Boutin, P.M. \& Neer, E.J. (1995) Interactions between the amino- and carboxyl-terminal regions of $G$ alpha subunits: Analysis of mutated $\mathrm{G}$ alpha $\mathrm{o} / \mathrm{G}$ alpha i2 chimeras. Biochemistry 34, 5544-5553.

31. Zhong, J.M., Chen-Hwang, M.C. \& Hwang, Y.W. (1995) Switching nucleotide specificity of Ha-Ras p21 by a single amino acid substitution at aspartate 119. J. Biol. Chem. 270, 10002-10007.

32. Schmidt, G., Lenzen, C., Simon, I., Deuter, R., Cool, R.H., Goody, R.S. \& Wittinghofer, A. (1996) Biochemical and biological consequences of changing the specificity of p21ras from guanosine to xanthosine nucleotides. Oncogene 12, 87-96.

33. Weijland, A., Parlato, G. \& Parmeggiani, A. (1994) Elongation factor Tu D138N, a mutant with modified substrate specificity, as a tool to study energy consumption in protein biosynthesis. Biochemistry 33, 10711-10717.

34. Scheidig, A.J., Franken, S.M., Corrie, J.E., Reid, G.P., Wittinghofer, A., Pai, E.F. \& Goody, R.S. (1995) X-ray crystal structure analysis of the catalytic domain of the oncogene product $\mathrm{p} 21 \mathrm{H}$-ras complexed with caged GTP and mant dGppNHp. J. Mol. Biol. 253, 132-150.

35. Berghuis, A.M., Lee, E., Raw, A.S., Gilman, A.G. \& Sprang, S.R. (1996) Structure of the GDP-Pi complex of Gly203Ala $\mathrm{G}_{\mathrm{i} \alpha}$ 1: A mimic of the ternary complex of $\mathrm{G}_{\alpha}$-catalyzed GTP hydrolysis. Structure 4, 1277-1290.

36. Frech, M., Darden, T.A., Pedersen, L.G., Foley, C.K., Charifson, P.S., Anderson, M.W. \& Wittinghofer, A. (1994) Role of glutamine-61 in the hydrolysis of GTP by p21H-ras: An experimental and theoretical study. Biochemistry 33, 3237-3244.

37. Schweins, T., Geyer, M., Scheffzek, K., Warshel, A., Kalbitzer, H.R. \& Wittinghofer, A. (1995) Substrate-assisted catalysis as a mechanism for GTP hydrolysis of p21ras and other GTP-binding proteins. Nat. Struct. Biol. 2, 36-44. 
38. Schweins, T., Scheffzek, K., Assheuer, R. \& Wittinghofer, A. (1997) The role of the metal ion in the p21ras catalysed GTP-hydrolysis: $\mathrm{Mn}^{2+}$ versus $\mathrm{Mg}^{2+}$. J. Mol. Biol. 266, 847-856.

39. Kosloff, M. \& Selinger, Z. (2001) Substrate assisted catalysis - application to G proteins. Trends Biochem. Sci. 26, 161-166.

40. Schweins, T. \& Warshel, A. (1996) Mechanistic analysis of the relationships in p21ras and related systems. Biochemistry 35, 1423214243.

41. Maegley, K.A., Admiral, S.J., Herschlag, D. (1996) Ras-catalyzed hydrolysis of GTP: A new perspective from model studies. Proc. Natl. Acad. Sci. U.S.A. 94, 8160-8166.

42. Tesmer, J.J.G., Berman, D.M., Gilman, A.G. \& Sprang, S.R. (1997) Structure of RGS4 bound to AIF $^{4-}$-activated $G_{i \alpha 1}$ : Stabilization of the transition state for GTP hydrolysis. Cell 89, 251-261.

43. Resat, H., Straatsma, T.P., Dixon, D.A. \& Miller, J.H. (2001) The arginine finger of RasGAP helps Gln-61 align the nucleophilic water in GAP-stimulate hydrolysis of GTP. Proc. Natl. Acad. Sci. U.S.A. 98, 6033-6038.

44. Sondek, J., Lambright, D.G., Noel, J.P., Hamm, H.E. \& Sigler, P.B. (1994) GTPase mechanism of $\mathrm{G}$ proteins from the $1.7-\AA$ crystal structure of transducin alpha-GDP-AIF ${ }^{-4}$. Nature 372, 276-279.

45. Cheng, H., Sukal, S., Callender, R. \& Leyh, T.S. (2001) Gamma-phosphate protonation and pH-dependent unfolding of the Ras $\square$ GTP $\square$ $\mathrm{Mg}^{2+}$ complex: A vibrational spectroscopy study. J. Biol. Chem. 276, 9931-9935.

46. Allin, C. \& Gerwert, K. (2001) Ras catalyzes GTP hydrolysis by shifting negative charges from gamma- to beta-phosphate as revealed by time-resolved FTIR difference spectroscopy. Biochemistry 40, 3037-3046.

47. Coleman, D.E., Berghuis, A.M., Lee, E., Linder, M.E., Gilman, A.G. \& Sprang, S.R. (1994)
Structures of active conformations of $\mathrm{G}_{\mathrm{i}}$ alpha 1 and the mechanism of GTP hydrolysis. Science 265, 1405-1412

48. Wall, M.A., Coleman, D.E., Lee, E., IniguezLluhi, J.A., Posner, B.A., Gilman, A.G. \& Sprang, S.R. (1995) The structure of the G protein heterotrimer $\mathrm{G}_{\mathrm{i}}$ alpha 1 beta 1 gamma 2 . Cell 83, 1047-1058.

49. Aspenstrom, P. (1999) Effectors for the Rho GTPases. Curr. Opin. Cell. Biol. 11, 95-102.

50. Maesaki, R., Shimizu, T., Ihara, K., Kuroda, S., Kaibuchi, K. \& Hakoshima, T. (1999) Biochemical and crystallographic characterization of a Rho effector domain of the protein serine/threonine kinase $\mathrm{N}$ in a complex with RhoA. J. Struct. Biol. 126, 166-170.

51. Sung, Y.J., Carter, M., Zhong, J.M. \& Hwang, Y.W. (1995) Mutagenesis of the H-ras p21 at glycine-60 residue disrupts GTP-induced conformational change. Biochemistry 34, 34703477.

52. Bauer, B., Mirey, G., Vetter, I.R., Garcia-Ranea, J.A., Valencia, A., Wittinghofer, A., Camonis, J.H. \& Cool, R.H. (1999) Effector recognition by the small GTP-binding proteins Ras and Ral. J. Biol. Chem. 274, 1776317770.

53. Herrmann, C., Horn, G., Spaargaren, M. \& Wittinghofer, A. (1996) Differential interaction of the ras family GTP-binding proteins H-Ras, Rap1A, and R-Ras with the putative effector molecules Raf kinase and Ral-guanine nucleotide exchange factor. J. Biol. Chem. 271, 6794-6800.

54. Nassar, N., Horn, G., Herrmann, C., Block, C., Janknecht, R. \& Wittinghofer, A. (1996) Ras/Rap effector specificity determined by charge reversal. Nat. Struct. Biol. 3, 723-729.

55. Geyer, M., Herrmann, C., Wohlgemuth, S., Wittinghofer, A. \& Kalbitzer, H.R. (1997) Structure of the Ras-binding domain of Ral guanine-nucleotide exchange factor: Implica- 
tions for Ras binding and signaling. Nat. Struct. Biol. 4, 694-699.

56. Pacold, M.E., Suire, S., Perisic, O., Lara-Gonzalez, S., Davis, C.T., Walker, E.H., Hawkins, P.T., Stephens, L., Eccleston, J.F. \& Williams, R.L. (2000) Crystal structure and functional analysis of Ras binding to its effector phosphoinositide 3-kinase gamma. Cell 103, 931-943.

57. Nassar, N., Horn, G., Herrmann, C., Scherer, A., McCormick, F. \& Wittinghofer, A. (1995) The $2.2 \AA$ crystal structure of the Ras-binding domain of the serine/threonine kinase c-Raf1 in complex with Rap1A and a GTP analogue. Nature 375, 554-560.

58. Mott, H.R., Carpenter, J.W., Zhong, S., Ghosh, S., Bell, R.M., Campbell, S.L. (1996) The solution structure of the Raf-1 cysteinerich domain: A novel Ras and phospholipid binding site. Proc. Natl. Acad. Sci. U.S.A. 93, 8312-8317.

59. Freed, E., Symons, M., MacDonald, S.G., McCormick, F. \& Ruggieri, R. (1994) Binding of 14-3-3 proteins to the protein kinase Raf and effects on its activation. Science $\mathbf{2 6 5}$, 1713-1716.

60. Therrien, M., Chang, H.C., Solomon, N.M., Karim, F.D., Wassarman, D.A. \& Rubin, G.M. (1995) KSR, a novel protein kinase required for RAS signal transduction. Cell 83, 879-888.

61. Therrien, M., Michaud, N.R., Rubin, G.M. \& Morrison, D.K. (1996) KSR modulates signal propagation within the MAPK cascade. Genes Dev. 10, 2684-2695.

62. Therrien, M., Wong, A.M. \& Rubin, G.M. (1998) CNK, a RAF-binding multidomain protein required for RAS signaling. Cell 95, 343-353.

63. Bishop, A.L. \& Hall, A. (2000) Rho GTPases and their effector proteins. Biochem. J. 348, 241-255.
64. Campbell, S.L., Khosravi-Far, R., Rossman, K.L., Clark, G.J. \& Der, C.J. (1998) Increasing complexity of Ras signaling. Oncogene 17, 1395-1413.

65. Bar-Sagi, D. \& Hall, A. (2000) Ras and Rho GTPases: A family reunion. Cell 103, 227-238.

66. Schalk, I., Zeng, K., Wu, S.K., Stura, E.A., Matteson, J., Huang, M., Tandon, A., Wilson, I.A. \& Balch, W.E. (1996) Structure and mutational analysis of Rab GDP-dissociation inhibitor. Nature 381, 42-48.

67. Gosser, Y.Q., Nomanbhoy, T.K., Aghazadeh, B., Manor, D., Combs, C., Cerione, R.A. \& Rosen, M.K. (1997) C-terminal binding domain of RhoGDP-dissociation inhibitor directs N-terminal inhibitory peptide to GTPases. $\mathrm{Na}$ ture 387, 814-819.

68. Scheffzek, K., Stephan, I., Jensen, O.N., Illenberger, D. \& Gierschik, P. (2000) The Rac-RhoGDI complex and the structural basis for the regulation of Rho proteins by RhoGDI. Nat. Struct. Biol. 7, 122-126.

69. Keep, N.H., Barnes, M., Barsukov, I., Badii, R., Lian, L.Y., Segal, A.W., Moody, P.C.E. \& Roberts, G.C.K. (1997) A modulator of rho family G proteins, RhoGDI, binds these G proteins via an immunoglobulin-like domain and a flexible N-terminal arm. Structure 5, 623-633.

70.Lian, L.Y., Barsukov, I., Golovanov, A.P., Hawkins, D.I., Badii, R., Sze, K.H., Keep, N.H., Bokoch, G.M. \& Roberts, G.C. (2000) Mapping the binding site for the GTP-binding protein Rac-1 on its inhibitor RhoGDI-1. Structure Fold. Des. 8, 47-55.

71. Longenecker, K., Read, P., Derewenda, U., Dauter, Z., Liu, X., Garrard, S., Walker, L., Somlyo, A.V., Nakamoto, R.K., Somlyo, A.P. \& Derewenda, Z.S. (1999) How RhoGDI binds Rho. Acta Crystallogr. D Biol. Crystallogr. 55, 1503-1515. 
72.Danley, D.E., Chuang, T.H. \& Bokoch, G.M. (1996) Defective Rho GTPase regulation by IL-1 beta-converting enzyme-mediated cleavage of D4 GDP dissociation inhibitor. $J$. Immunol. 157, 500-503.

73. Nomanbhoy, T.K. \& Cerione, R. (1996) Characterization of the interaction between RhoGDI and Cdc42Hs using fluorescence spectroscopy. J. Biol. Chem. 271, 10004-10009.

74. Scheffzek, K., Lautwein, A., Kabsch, W., Ahmadian, M.R. \& Wittinghofer, A. (1996) Crystal structure of the GTPase-activating domain of human p120GAP and implications for the interaction with Ras. Nature 384, 591-596.

75. Rittinger, K., Walker, P.A., Eccleston, J.F., Smerdon, S.J. \& Gambin, S.J. (1997) Structure at $1.65 \AA$ of RhoA and its GTPase-activating protein in complex with a transition state analog. Nature 389, 758-762.

76. Barrett, T., Xiao, B., Dodson, E.J., Ludbrook, S.B., Nurmahomed, K., Ganbin, S.J., Smerdon, S.J. \& Eccleston, J.F. (1997) The structure of the GTPase-activating domain form p50rhoGAP. Nature 385, 458-461.

77. Souchet, M., Poupon, A., Callebaut, I., Leger, I., Mornon, J., Bril, A. \& Calmels, T.P. (2000) Functional specificity conferred by the unique plasticity of fully alpha-helical Ras and Rho GAPs. FEBS Lett. 477, 99-105.

78. Longenecker, K.L., Zhang, B., Derewenda, U., Sheffield, P.J., Dauter, Z., Parsons, J.T., Zheng, Y. \& Derewenda, Z.S. (2000) Structure of the $\mathrm{BH}$ domain from Graf and its implications for Rho GTPase recognition. J. Biol. Chem. 275, 38605-38610.

79. Drugan, J.K., Rogers-Graham, K., Gilmer, T., Campbell, S. \& Clark, G.J. (2000) The Ras/p120 GTPase-activating protein (GAP) interaction is regulated by the p120 GAP pleckstrin homology domain. J. Biol. Chem. 275, 35021-35027.
80. Rittinger, K., Walker, P.A., Eccleston, J.F., Nurmahomed, K., Laue, E., Owen, D., Ganbin, S.J. \& Smerdon, S.J. (1997) Crystal structure of a small $G$ protein in complex with the GTPase-activating protein RhoGAP. Nature 388, 693-697.

81. Renault, L., Kuhlmann, J., Henkel, A. \& Wittinghofer, A. (2001) Structural basis for guanine nucleotide exchange on Ran by the regulator of chromosome condensation (RCC1). Cell 105, 245-255.

82. Boriack-Sjodin, P.A., Margarit, S.M., Bar-Sagi, D. \& Kuriyan, J. (1998) The structural basis of the activation of Ras by Sos. $\mathrm{Na}$ ture 394, 337-343.

83. Cherfils, J., Menetrey, J., Mathieu, M., Le Bras, G., Robineau, S., Beraud-Dufour, S., Antonny, B. \& Chardin, P. (1998) Structure of the Sec7 domain of the Arf exchange factor ARNO. Nature 392, 101-105.

84. Yu, H. \& Schreiber, S.L. (1995) Structure of guanine-nucleotide-exchange factor human Mss4 and identification of its Rab-interacting surface. Nature 376, 788-791.

85. Hart, M.J., Jiang, X., Kozasa, T., Roscoe, W., Singer, W.D., Gilman, A.G., Sternweis, P.C. \& Bollag, G. (1998) Direct stimulation of the guanine nucleotide exchange activity of p115 RhoGEF by Galpha13. Science 280, 21122114.

86. Hart, M.J., Roscoe, W. \& Bollag, G. (2000) Activation of Rho GEF activity by G alpha 13 . Methods Enzymol. 325, 61-71.

87. Fukuhara, S., Murga, C., Zohar, M., Igishi, T. \& Gutkind, J.S. (1999) A novel PDZ domain containing guanine nucleotide exchange factor links heterotrimeric G proteins to Rho. J. Biol. Chem. 274, 5868-5879.

88. Hart, M.J., Eva, A., Zangrilli, D., Aaronson, S.A., Evans, T., Cerione, R.A. \& Zheng, Y. (1994) Cellular transformation and guanine nucleotide exchange activity are catalyzed by a 
common domain on the $d b l$ oncogene product. J. Biol. Chem. 269, 62-65.

89.Zheng, Y., Fischer, D.J., Santos, M.F., Tigyi, G., Pasteris, N.G., Gorski, J.L. \& Xu, Y. (1996) The faciogenital dysplasia gene product FGD1 functions as a Cdc42Hs-specific guanine-nucleotide exchange factor. J. Biol. Chem. 271, 33169-33172.

90. Steven, R., Kubiseski, T.J., Zheng, H., Kulkarni, S., Mancillas, J., Ruiz, Morales, A., Hogue, C.W., Pawson, T. \& Culotti, J. (1998) UNC-73 activates the Rac GTPase and is required for cell and growth cone migrations in C. elegans. Cell 92, 785-795.

91. Horii, Y., Beeler, J.F., Sakaguchi, K., Tachibana, M. \& Miki, T. (1994) A novel oncogene, ost, encodes a guanine nucleotide exchange factor that potentially links Rho and Rac signaling pathways. EMBO J. 13, 4776-4786.

92. de Bruyn, K.M., de Rooij, J., Wolthuis, R.M., Rehmann, H., Wesenbeek, J., Cool, R.H., Wittinghofer, A.H. \& Bos, J.L. (2000) RalGEF2, a pleckstrin homology domain containing guanine nucleotide exchange factor for Ral. J. Biol. Chem. 275, 29761-29766.

93. Musacchio, A., Gibson, T., Rice, P., Thompson, J. \& Saraste, M. (1993) The PH domain: A common piece in the structural patchwork of signalling proteins. Trends Biochem. Sci. 18, 343-348.

94. Whitehead, I.P., Campbell, S., Rossman, K.L. \& Der, C.J. (1997) Dbl family proteins. Biochim. Biophys. Acta 1332, F1-F23.
95. Pawson, T. (1995) Protein modules and signalling networks. Nature 373, 573-580.

96. Aghazadeh, B., Zhu, K., Kubiseski, T.J., Liu, G.A., Pawson, T., Zheng, Y. \& Rosen, M.K. (1998) Structure and mutagenesis of the Dbl homology domain. Nat. Struct. Biol. 5, 10981107.

97. Soisson, S.M., Nimnual, A.S., Uy, M., Bar-Sagi, D. \& Kuriyan, J. (1998) Crystal structure of the Dbl and pleckstrin homology domains from the human Son of sevenless protein. Cell 95, 259-268.

98. Zheng, J., Chen, R.H., Corblan-Garcia, S., Cahill, S.M., Bar-Sagi, D. \& Cowburn, D. (1997) The solution structure of the pleckstrin homology domain of human SOS1. A possible structural role for the sequential association of diffuse B cell lymphoma and pleckstrin homology domains. J. Biol. Chem. 272, 30340-30344.

99.Zhang, B., Zhang, Y., Wang, Z. \& Zheng, Y. (2000) The role of $\mathrm{Mg}^{2+}$ cofactor in the guanine nucleotide exchange and GTP hydrolysis reactions of Rho family GTP-binding proteins. J. Biol. Chem. 275, 25299-25307.

100. Cherfils, J. \& Chardin, P. (1999) GEFs: Structural basis for their activation of small GTP-binding proteins. Trends Biochem. Sci. 24, 306-311. 